\title{
Neoclassical Growth, Manufacturing Agglomeration, and Terms of Trade
}

\author{
Urban, Dieter M.
}

Document Version

Final published version

Publication date:

1998

License

CC BY-NC-ND

Citation for published version (APA):

Urban, D. M. (1998). Neoclassical Growth, Manufacturing Agglomeration, and Terms of Trade. Department of Economics. Copenhagen Business School. Working Paper / Department of Economics. Copenhagen Business School No. 16-98

Link to publication in CBS Research Portal

\footnotetext{
General rights

Copyright and moral rights for the publications made accessible in the public portal are retained by the authors and/or other copyright owners and it is a condition of accessing publications that users recognise and abide by the legal requirements associated with these rights.

Take down policy

If you believe that this document breaches copyright please contact us (research.lib@cbs.dk) providing details, and we will remove access to the work immediately and investigate your claim.
}

Download date: 26. Apr. 2023 


\section{Institut for Nationaløkonomi}

Handelshøjskolen i København

Working paper 16-98

NEOCLASSICAL GROWTH, MANUFACTURING AGGLOMERATION, AND TERMS OF TRADE

Dieter M. Urban

Department of Economics - Copenhagen Business School

Nansensgade 19, 5. DK - 1366 København K. 
November 17, 1998

\title{
Neoclassical Growth, M anufacturing A gglomeration, and Terms of Trade
}

\author{
By \\ Dieter M. URBAN \\ Copenhagen Business School, Denmark.
}

\begin{abstract}
A bstract
This paper presents an integrated view of economic growth, development traps, and economic geography. We explain why there is income convergence among some countries (neoclassical regime) and income divergence among others (poverty trap regime). Income convergence (divergence) and manufacturing industry diausion (agglomeration) are re-enforcing each other in a cumulative process. Moreover, trade openness may trigger a catch-up process of an economy that is stuck in a "poverty trap". This catch-up is characterized by an increase in the investment-to-GDP ratio and an improvement of the terms of trade.
\end{abstract}

J EL Classi..cation: F 12, 041

K eywords: convergence, agglomeration, poverty trap, terms of trade, complementarities

M ailing Address: Dieter M. Urban, Department of E conomics, Copenhagen Business School, Nansensgade 19, 5th ¥oor, DK-1366 Copenhagen K, Denmark.

${ }^{\circledR}$ T he author thanks Niels B lomgren-Hansen, M arkus B ollig, Eric B ond, Bjarne Sloth J ensen, Pascalis R aimondos-M oller, and seminar participants of Copenhagen B usiness School, PennState University, the EEA-conference in Toulouse 1997, and the Midwest-International-E conomics conference in Bloomington 1997 for their comments. Usual caveats apply. 


\section{Introduction}

Economic geography is the sub..eld of economics that explains the location of production factors in space. Growth theory is the sub..eld of economics that explains national or regional income both across time and across countries or regions. The theory of development traps explains why some countries or regions lack behind. In this paper, we will explore the interrelation of these three sub..elds. ${ }^{1 ; 2}$

Such an interrelation between growth theory, the location of manufacturing industries, and the backwardness of some regions or countries has been discussed informally among others by Myrdal and Kaldor. In particular, Myrdal (1957) observes and explains disparities both in regional and in national incomes. Additionally, Kaldor (1967) builds his growth theory upon Myrdal's work being more explicit about underlying assumptions and transmission channels. We consider ..ve stylised facts that may capture the main theses of Myrdal (1957) and Kaldor (1967).

1) The same force that explains the agglomeration of economic activity in space also explains national dixerences in income.

"The international inequalities are, of course, not dissimilar from the regional inequalities within a country. We will also ..nd that there is a close causal relation between the two." (Myrdal, 1957, p. 10)

2) This force is based on the "principle of circular and cumulative causation" (Myrdal, 1957, chapter 2). Myrdal describes this principle as a self-enforcing process that is explicitly thought of as an unstable equilibrium of a dynamical system that drives one country or region into a best position and another country or region

\footnotetext{
${ }^{1}$ Lucas (1988) also accounts for all three sub..elds at once. He starts out with a theory that ..ts the stylised facts of the US growth experience and explains within this setting 1) why income dixers among countries, and 2) why international trade is not insuring convergence of income. Lucas (1988) ..nally points out that "a national economy is a completely arbitrary unit to consider" (p. 37) and accounts in his setting for the formation of cities by human capital externalities. We will base our model on an endogenous explanation, rather than an externality to explain many of the same stylised facts.

${ }^{2}$ Thereby we will follow a modeling approach that tries to capture many stylised facts in a model mechanism that is as simple as possible. Of course, none of the stylised facts will be exclusively explained by our model.
} 
into a worst position. Myrdal (1957, p. 27 ) notes further that migration, capital movements, and trade may keep regional disparities growing.

3) The crucial assumption deviating from neoclassical theory is increasing returns to scale production technology (K aldor, 1967, lecture 1 ). Increasing returns to scale applies, according to $\mathrm{K}$ aldor, particularly to a wide range of manufacturing industries and might become exective not so much in terms of ..rm size, but in terms of process and product dixerentiation.

"Economies of scale are derived not only from the expansion from any single industry but from a general industrial expansion ..." (K aldor, 1967, p.14)

4) A possible transmission channel may be a terms-of-trade exect.

"A cumulative process of the same general character, ..., will also be generated by a change in the terms of trade of a community or a region, if the change is large and persistent enough ..." (Myrdal, 1957, p. 26)

5) A nother possible part of a transmission channel may be internal capital accumulation of a region or country that drives up the return on investment in the faster growing regions relative to the slower growing regions. In this sense investment projects may be complements, rather than substitutes.

"The establishment of a new business or the enlargement of an old one widens the market for others, as does generally the increase of income and demand. Rising pro..ts increase savings, but at the same time investments go up still more, which again pushes up the demand and the level of profits. And the expansion process creates external economies favourable for sustaining its continuation." (M yrdal, 1957, p. 25) 
We conclude: If the same force explains manufacturing industry agglomeration and income disparities, this calls for a uni..ed approach of growth theory and economic geography. We will set up a model that captures all the above ..ve theses. This rises a question: Why should one try to model income divergence? After all, the neoclassical view of economic growth, i.e. (conditional) convergence of income at least among some countries, has found large approval among mainstream economists. ${ }^{3}$

The recent empirical convergence literature is inconclusive of the (conditional) convergence hypothesis (Barro, 1991, Barro and Sala-i-Martin, 1992, and Mankiw, Romer, and Weil, 1992 and Cohen, 1996) or the club convergence hypothesis (Baumol, et. al., 1989, Durlauf and J ohnson, 1996, and Quah, 1996) for both country and regional data sets. On the one hand, Barro (1991), Barro and Sala-i-Martin (1992), Mankiw, Romer and Weil (1992), and Cohen (1996) ..nd that the average country or region converges conditionally on structural characteristics of the economies. On the other hand, Quah (1997) notes that the population of the converging regions/ countries might be double peaked, thus supporting the club convergence hypothesis which says that initial conditions also matter. Additionally, Durlauf and J ohnson (1995) reject the conditional convergence hypothesis in favour of multiple regimes or stages of development in a cross section analysis. ${ }^{4}$ Quah (1993) notes also that conditional convergence of the average country in a regression analysis is compatible with outlier countries that do not converge. ${ }^{5}$

The theory on development traps explains these countries that do not converge to a "rich country" steady state. ${ }^{6}$ However, given that there is a theory on economic growth that predicts conditional convergence, and a theory on development traps

\footnotetext{
${ }^{3}$ Independently of the empirical convergence literature, there is other empirical evidence supporting the neoclassical growth model. J ones (1995) and Levine and Renelt (1992) show that the time series properties of endogenous growth models are inconsistent with the data and that the growth regressions are unrobust with respect to most independent variables except investment. Furthermore, Young (1995) shows that the East A sian growth miracles can be explained by factor accumulation in the spirit of the neoclassical growth model, rather than by total factor productivity growth. However, Caselli, Esquivel, and Lefort (1996) claim reduced empirical relevance of the Solow model on basis of GMM -estimation.

4J ones (1997) adds that the relatively rich countries tend to converge, whereas the relatively poor countries tend to converge from the US per capita income levels.

${ }^{5}$ T he classical example is the Italian Mezzogiorno - a region of relative and absolute decline over decades. See Rauch (1997).

${ }^{6}$ Surveys on poverty trap models are Azariadis (1996) and Galor (1996).
} 
that predicts some sort of divergence, one may pose the following question: When is a country described by the ..rst theory and when by the second? To answer this question, a uni..ed approach may prove helpful having a "neoclassical regime" that has all the properties of a neoclassical growth model, having a "poverty trap regime" that explains backwardness, and having a testable condition under which one or the other regime prevails. This paper attempts to provide such an approach.

Our ..rst contribution will be to integrate Myrdal's and K aldor's view on economic growth, development traps and the location of production factors - summarized in the ..ve theses above - into mainstream economics without any sacri..ce of neoclassical theory. Additionally, we will state a testable condition under which the one or the other regime applies.

Our second contribution will be to focus on a new agglomeration process of manufacturing industries among countries that is based on a mutual interaction with capital accumulation and growth. Agglomeration of economic activity on dixerent levels like city, region, or nation may be explained by dixerent agglomeration forces. ${ }^{7}$ Cities may be formed by localized intermediate inputs (A bdel-R ahman (1988), Fujita (1988), Rivera-Batiz (1988), and in a growth setting Englmann and Walz (1995)). Disparities among regions may be caused by factor movements such as worker migration (K rugman, 1991a), or forward and backward linkages caused by intermediate goods (Venables, 1996). Internationally, frictionless factor movements are less likely to happen than interregionally. ${ }^{8}$ But what causes then an unequal distribution of manufacturing industries among countries? One answer is specialization of countries in dixerent sectors (e.g. Krugman and Venables, 1995); another one is information externalities (Grossman and Helpman, 1991); and a third answer is R\&D location decisions (Martin and Ottaviano, 1996). The simplest explanation is, however, that there are more manufacturing ..rms in one country relative to another, because this country has accumulated more capital. This alone does not suф ce for an explanation.

\footnotetext{
${ }^{7}$ Fujita and Thisse (1996) survey the literature on agglomeration economics. We consider only endogenous explanations in cumulative processes, such that completely identical countries end up diverging from each other if there is just a small disturbance (idiosyncratic shock).

${ }^{8}$ See K rugman and Venables (1995).
} 
The missing part is how ..rm agglomeration feeds back on diverging capital accumulation. How does an increase of agglomeration lead to higher growth of a country relative to another, and higher growth to even higher ..rm agglomeration? We will explain this feed-back with a terms-of-trade exect. ${ }^{9}$

Our third contribution will be to explain how trade-liberalization triggers a catch-up process. It is obvious that the agglomeration forces depend crucially on the costs of bridging distances (e.g. transport cost, tarixs, information costs, etc.), because otherwise location does not matter. If agglomeration happens at a high level of trade costs and convergence at a low level, and manufacturing agglomeration or convergence feed through on growth, then we have established a (new) nexus between trade-liberalization and growth.

The rest of the paper is organized as follows: section 2 gives a brief verbal description of the model and its mechanics, and compares related literature; section 3 gives the formal model set-up; section 4 solves the model for the steady states; section 5 provides a stability analysis; section 5.1 discusses the neoclassical growth regime; section 5.2 discusses the "poverty trap" regime; section 5.3 gives the model implications for economic geography; and section 6 concludes.

\section{A Brief Model Description}

Our model is a synthesis of an economic geography model (K rugman, 1991a) and a neoclassical growth model (Solow, 1956, and others). There are two countries that have a Dixit-Stiglitz (1977) monopolistic competition production sector with increasing returns on plant level. Labour and capital are immobile. Capital is a durable goods composite of all varieties. Investment is taken literally as foregone consumption. There is intra-industry trade, although trade costs segment the product markets in the two countries and trade is assumed to be balanced. Consequently, the only linkage between the two countries are the terms of trade.

\footnotetext{
${ }^{9} \mathrm{An}$ alternative nexus is given recently in Ben-David and Loewy (1998) based on cross-country

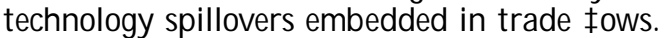


The mechanics of the model are best understood in a thought experiment. Suppose two identical countries grow symmetrically having a capital stock of identical size. For some reason (idiosyncratic shock), country 1's capital stock grows faster than country 2's at one time period. This will increase the number of ..rms in country 1 relative to country 2 given that output per ..rm remains constant. ${ }^{10}$ B ecause of trade costs, there is a home market bias in consumption of goods. Additionally, income is higher in country 1 , because there is more capital. Hence, there will be stronger demand for any typical variety in country 1 relative to any typical variety in country 2, whereas relative supplies for a typical variety do not change. This will increase country 1's producer price of a typical variety relative to country 2's (terms-of-trade exect).

The savings and investment decision in each country is based on the present and future real interest rate which is equal to the real rental rate of capital. The real rental rate in each country at a given point in time is infuenced by three exects: (i) The higher producer prices in country 1 allow ceteris paribus for higher rental rates in country 1 (agglomeration force I). (ii) There are less goods to be imported in country 1. Therefore, there are less trade costs to be paid and the consumption price index is thus lower in country 1 . This means - everything else equal - that the real interest rate is higher in country 1 (agglomeration force II). (iii) The capital-labor ratio is higher in country 1. By capital-labour substitutability, this implies a higher wage-rental rate in country 1 (convergence force). The net exect of the three forces turns out to be ambiguous and depends on the level of trade costs.

Suppose the real rental rate in country 1 decreases faster than the one in country 2 over the entire transition path towards the steady state (spatial substitutability of investment). Then, investment will be lower in country 1 over the entire transition path and the two capital stocks will eventually converge over time. This implies income

\footnotetext{
${ }^{10} \mathrm{~T}$ his is a standard result in a Dixit-Stiglitz (1977) set-up due to the assumption of CES utility functions and constant variable cost. Suppose there is an expansion in total income. Then demand for each single good is rising. This rises pro..ts for all (symmetric) ..rms, because the ..xed cost can be spread over a larger output. However, the increase in pro..ts causes new ..rms to enter, such that the original increase in income is now spread over more goods. The amount of income spent on a single good falls back to the original level. Therefore, output of a single ..rm is a constant in this set-up.
} 
convergence and describes thus the neoclassical regime. Suppose, on the contrary, that the real rental rate decreases slower in country 1 than in country 2 over the entire time path (spatial complementarity of investment). Then, future investment will be higher in country 1. This increases further the terms of trade in country 1 . Thus, the real rental rate gap might become even bigger self-enforcing the faster capital accumulation in country 1 . The cumulative process will eventually stop as the convergence force will begin to dominate at some degree of divergence. This implies income divergence and describes thus the "poverty trap" regime. If in this regime the capital stock is higher in country 1 at any point of time, then a ..xed ..rm size implies an agglomeration of ..rms in country 1 . Hence, a new explanation for manufacturing industry agglomeration is found that is based both on national capital accumulation and a terms-of-trade exect in a cumulative process.

Our model builds upon the literature on big push and poverty traps which was promoted in an inłuential formal model by Murphy, Shleifer, and Vishny (1989). We share the features of increasing returns technology and demand spillovers to trigger self-enforcing growth processes. However, we pose this idea into an international context allowing us to discuss the importance of trade barriers, and home-market size, and the role of neighbouring countries in boosting or inhibiting growth.

Gali (1995) builds into a model with monopolistic competition an investment complementarity by a competition exect that drives a wedge between the physical marginal product of capital and the marginal revenue product of capital. Instead of the competition exect in a closed economy, we use a terms-of-trade exect in a two country model to generate a relative investment complementarity rather than an absolute one. ${ }^{11}$

Our model is also related to Baldwin, Forslid, and Haaland (1995) which inspired our model set-up and Baldwin and Seghezza (1996). These models have similar production, consumption and market structures as ours. However, their focus is on

\footnotetext{
${ }^{11}$ T hat is a rise in the relative capital stock of two countries rises the ratio of real rental rates, whereas in Gali (1995) an absolute rise in the capital stock rises (locally) the absolute value of the real rental rate.
} 
dynamic gains of trade and on the investment creation of trade liberalization in the symmetric country case. They rule out terms-of-trade exects and exclude the cumulative process that we focus on. ${ }^{12}$

\section{The Model Set-up}

There are two consumers which dixer only by their place of residence in two countries $(j=1 ; 2)$. A standard logarithmic intertemporal utility function $U_{j}$ is assumed ${ }^{13}$ that is de..ned on a consumption basket $C_{j}$ :

$$
\begin{aligned}
& \text { I } \\
& U_{j}=e_{0}^{i \cdot t} \ln C_{j} d t ;
\end{aligned}
$$

where, is the time preference rate, and $t$ is a time index in continuous time. ${ }^{14}$ The consumption basket $C_{j}$ of a consumer $j$ is of the Dixit-Stiglitz (1977) type and is de..ned on all domestic and foreign produced varieties with an elasticity of substitution denoted $3 / 4(3 / 4>1)$ :

$$
C_{j}=@_{i_{j}=1}^{0} \frac{c_{i_{j} j}^{n_{j} / 4 / 4}}{n_{1}+n_{2}}+x_{i_{k}=1}^{n_{k}} \frac{c_{i_{k} j / 4}^{\frac{3 / 4}{3 / 4}}}{n_{1}+n_{2}} A^{1} ;
$$

where the number of goods produced in country $\mathrm{j}$ are indexed $\mathrm{i}_{\mathrm{j}}=\mathrm{l}_{\mathrm{j}} ;: ; ; ; \mathrm{n}_{\mathrm{j}}$; and $c_{i_{j} j}$ and $c_{i_{k} j} ; j ; k=1 ; 2 ; k=j$; are consumer $j$ 's consumption of the varieties $i_{j}$ and $\mathrm{i}_{\mathrm{k}}$ produced in country $\mathrm{j}$ and $\mathrm{k}$, respectively. Additionally, there is no international borrowing and lending and trade will have to be balanced. ${ }^{15}$

\footnotetext{
${ }^{12}$ Very recently, Baldwin (1998), Baldwin, Martin, and Ottaviano (1998), and Baldwin and Forslid $(1997,1998)$ expell the same idea of bifurcation of income convergence/ divergence behavior of two economies in dependence of trade cost in a model with monopolistic competition and increasing returns. However, our engine of growth is capital accumulation, and our convergence force Solow's (1956) capital-labor substitutability assumption, whereas the papers above use technological progress as engine of growth and the extent of competition exect of economic geography models (K rugman, 1991a) as convergence force. Consequently, trade openness triggers income divergence in Baldwin, Martin, and Ottaviano (1998), whereas in our model trade openness triggers income convergence. Also, a larger home market increases ..rm pro..ts and $R \& D$ activity in the papers mentioned above, whereas a larger home market induces a demand bias towards domestic goods and rises the domestic terms of trade in our model.

${ }^{13} \mathrm{~A} / l$ results remain valid, if an isoelastic intertemporal utility function is used. However, mathematical proofs would be more complicated.

${ }^{14}$ We suppress the time index whenever obvious.

${ }^{15} \mathrm{~T}$ he assumption of balanced trade has a long tradition in the trade and growth literature: e.g. Stiglitz (1970) and Grossman and Helpman (1991).
} 
With monopolistic competition, each variety $i_{j}$ will be produced by a dixerent ..rm $\mathrm{i}_{\mathrm{j}}$. Firms dixer only by their location. Therefore, ..rms within a country $\mathrm{j}$ are symmetric and the index $i_{j}$ for ..rm $i$ in country $j$ can be collapsed to $j$ denoting a typical ..rm in country $\mathrm{j}:$ The production technology is a Cobb-Douglas production function with ..xed cost that gives rise to increasing returns to scale on plant level. In particular, ${ }^{\circledR}$ units of inputs $v_{j}$ in form of a basket of labour $l_{j}$ and capital $k_{j}$ are used to install the production process every day (maintenance work) and - units of the input basket are used to produce each unit of goods for the domestic and the foreign market $x_{j}$ :

$$
V_{j}={ }^{\circledR}+{ }^{-} x_{j} \quad \text { and } \quad V_{j}=k_{j}^{*} j_{j}^{1} \pm,
$$

where $\pm(0< \pm<1)$ denotes the income share of capital. ${ }^{16}$

We assume as in Baldwin, Forslid and Haaland (1995) that investment and capital are the same composite of industrial goods as is consumption and goods can be used both for consumption and investment:

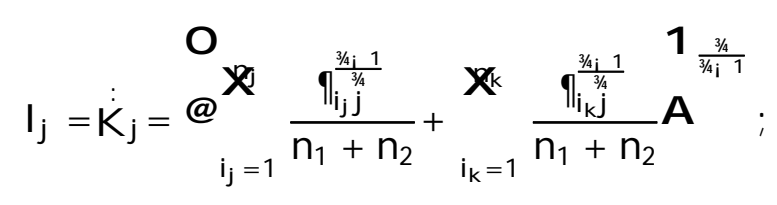

where $I_{j}$ is the investment aggregate used by the .rms in country $j$ to increase the capital stock $K_{j}$ of country $j$, a dot denotes the time derivative of a variable, and $\mathbf{q}_{j} j$ and $\boldsymbol{I}_{k} ; j ; k=1 ; 2 ; k=j$; are demand of the ..rms in country $j$ for investment goods produced by a ..rm $i_{j}$ and $i_{k}$ in country $j$ and $k$, respectively. A unit of capital, i.e. a machine, may be assembled at zero cost in dixerent ways from time-varying product spaces, but once it is assembled it performes the same service. A larger product space does not allow for more productive capital (no Smithian growth). ${ }^{17}$ Note that we do not allow for the usual depreciation of capital. One can think of capital as a

\footnotetext{
${ }^{16}$ It will be this particular type of the production function that guarantees both constancy of factor shares (K aldor, 1963), and constant returns to scale on industry level (Burnside, 1996).

${ }^{17} \mathrm{Smithian}$ growth, i.e. the cost reduction from larger market size and increased specialisation, is discussed in K elly (1997) in the context of economic geography and growth.
} 
durable composite of intermediate input goods that is permanently maintained. The maintenance cost will show up in the ..xed cost parameter $®$ of the production function.

Additionally, we assume free ..rm entry and exit which keeps pro..ts at zero. Production factors are immobile. ${ }^{18}$ For simplicity, labour supply is inelastic, equally distributed among countries, and normalized to one ${ }^{19}$. Finally, there are trade costs of the Samuelson iceberg-type, such that only a fraction $i$ of one produced unit of a good arrives at its foreign destination $(0<i<1)$.

\section{Equilibrium}

The consumption maximization problem of the typical agents in country 1 and 2 may be solved in two stages. First, the demand for any variety is determined for any given time path of expenditure on consumption goods. The corresponding unit expenditure function or ideal CES price index $\mathrm{P}_{\mathrm{j}}$ is found to be: ${ }^{20}$

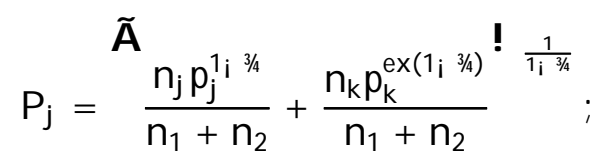

where $p_{\mathrm{j}}$ and $p_{\mathrm{k}}^{\mathrm{ex}}$ are the domestic producer prices and export prices of ...rms in country $\mathrm{j}$ and $\mathrm{k}$ charged for consumers in country j, respectively. Then, the individual budget constraint can be written as follows: ${ }^{21}$

$$
\mathrm{K}_{j}^{\mathrm{d}}=\mathrm{I}_{\mathrm{j}}=\frac{\mathrm{r}_{\mathrm{j}} \mathrm{K}_{\mathrm{j}}}{P_{\mathrm{j}}}+\frac{W_{j}}{P_{j}} \mathrm{i} C_{j}
$$

where $r_{j}$ and $w_{j}$ denote nominal rental and wage rates. Investment expenditure equals wage income and rents minus consumption expenditure. Second, the optimal con-

\footnotetext{
${ }^{18}$ We make this assumption, because we want to distinguish our agglomeration process from that of Krugman (1991a), K rugman and Venables (1995), Venables (1996), and Martin and Ottaviano (1996). These papers rely on interregional or intersectoral factor (in particular labour) movements and $R \& D$ location decisions.

19 If we did not assume this normalization, then the capital stocks would simply be replaced by the capital-labor ratios. None of the qualitative results obtained in this paper would change, of course.

${ }^{20} \mathrm{~N}$ ote that we take here the symmetry of ..rms within a country into account.

${ }^{21}$ We use the de..nition of the expenditure function (and an analogous equation for the investment aggregate $I_{j}$ ):

$$
P_{j} C_{j},{ }_{i_{j}=1}^{x_{j}} p_{j} c_{i_{j} j}+{ }_{i_{k}=1}^{x_{k}} p_{k}^{e x} c_{i_{k} j}
$$
}


sumption expenditure is determined by maximizing utility (1) taking the individual budget constraint (6), a price vector, and the initial condition as given. We assume that private agents do not foresee the impact of their behaviour on decisions of agents in the other country. This assumption excludes strategic interaction and is in line with the monopolistic competition conjecture. The optimization yields the familiar Euler equation: ${ }^{22}$

$$
\dot{C}_{j}={ }^{i} / \frac{2}{i}, C_{j}
$$

where $1 / \mathrm{f}^{\prime} \quad r_{\mathrm{j}}=P_{\mathrm{j}}$ denotes the real rental rate of capital. Additionally, the familiar transversality condition completes the description of the dynamical system. N ote that the steady state condition of the emerging dynamical system will involve equalization of real rental rates of capital across countries.

Firms maximize pro..ts and use a mark-up pricing rule given the imperfect competition conjecture of Dixit and Stiglitz (1977) that ..rms take the direct impact of their price decision on goods market demand into account, but not the indirect exects on income and the price index: ${ }^{23}$

$$
p_{j}=\frac{3 / 4}{3 / 4 j 1}-c\left(w_{j} ; r_{j}\right) \quad \text { and } \quad p_{j}^{e x}=\frac{3 / 4}{3 / 4 i} 1^{-} c\left(w_{j} ; r_{j}\right)=i:
$$

It is important that prices for foreign consumers contain a transport-cost mark-up on prices for domestic consumers. Furthermore, $c\left(w_{j} ; r_{j}\right)$ denotes the unit cost function which is given by the following expression:

$$
c\left(w_{j} ; r_{j}\right)=\left(1 ; \quad \Psi^{ \pm 1} \Psi^{ \pm}{ }^{ \pm} r_{j}^{ \pm} w_{j}^{1_{i}} \pm\right.
$$

Finally, the relative input demand determines after aggregation the wage-rental ratio for a given capital-labour ratio (Recall that labour endowments are normalized to one.):

$$
\frac{W_{j}}{r_{j}}=\frac{1_{i} \pm}{ \pm} K_{j}:
$$

Capital letters denote aggregates (e.g. $K_{j}{ }^{\prime} n_{j} k_{j}$ and $\left.V_{j}{ }^{\prime} n_{j} v_{j}\right)$. Additionally, the zero pro..t condition $n_{j} p_{j} x_{j}=r_{j} K_{j}+w_{j}$ holds due to free ..rm entry and exit. Hence,

\footnotetext{
${ }^{22}$ We follow the standard procedure as in Barro and Sala-i-M artin (1995).

${ }^{23} \mathrm{~F}$ or a discussion of this conjecture see d'A spremont, et. al. (1996).
} 
we ..nd from the zero pro..t condition and equation (10) that the rental payments are a constant fraction of income:

$$
r_{j} K_{j}= \pm n_{j} p_{j} x_{j}:
$$

Using the zero pro..t condition, we derive the following equation for ..rm output: ${ }^{24}$

$$
\mathrm{x}_{\mathrm{j}}=\overline{\mathrm{X}}=1 ;
$$

where we normalized without loss of generality ${ }^{-}=1 \mathrm{i} \quad \circledR$ and ${ }^{3} / 4=1 .{ }^{25}$ Factor market equilibrium requires:

$$
n_{j}=K_{j}^{ \pm}=V_{j}:
$$

Thus, the number of ...rms and goods depends on the capital stock of a country. The goods market equilibrium condition for a typical ..rm in country 1 at any point of time is the last equilibrium condition to be imposed: ${ }^{26}$

$$
\frac{p_{1}^{i^{3 / 4}}\left(r_{1} K_{1}+w_{1}\right)}{n_{1} p_{1}^{1_{i}^{3 / 4}}+q n_{2} p_{2}^{1_{i} 3^{3 / 4}}}+\frac{q p_{1}^{i^{3 / 4}}\left(r_{2} K_{2}+w_{2}\right)}{q n_{1} p_{1}^{1_{i}^{3 / 4}}+n_{2} p_{2}^{1_{i}^{3 / 4}}}=1:
$$

where $q^{\prime} i^{3 / 41}$ proxies the reciprocal of trade costs for notational simplicity. U sing the zero pro..t condition and de. ning relative producer prices (terms of trade) $p^{\prime} \quad p_{2}=p_{1}$ and relative ..rm agglomeration $n^{\prime} n_{2}=n_{1}$, equation (14) can be reformulated in the following way:

$$
\frac{1}{1+q n p^{1_{i}^{3 / 4}}}+\frac{q n p}{q+n p^{1_{i}^{3 / 4}}}=1
$$

which can be solved for $n$ to give two solutions $n=0$ and

$$
n=\frac{q_{i} p^{3 / 4}}{p\left(q_{i} p^{3 / 4}\right)} \quad \text { with } \quad 0<n<1:
$$

This simple equation gives a relationship between the terms of trade and relative ..rm agglomeration.

\footnotetext{
${ }^{24}$ For the derivation, we use the de. nition of $V_{j}$, equations ( 3 ) and (8), and $c\left(w_{j} ; r_{j}\right) V_{j}=r_{j} K_{j}+w_{j}$ which is obtained by plugging (11) and its counterpart for labour demand into the de..nition of $V_{j}$, deviding through by $c\left(w_{j} ; r_{j}\right)$, and applying the zero pro..t condition.

${ }^{25} \mathrm{~A} / \mathrm{ll}$ results of the model are independent of $\circledR$ and ${ }^{-}$.

${ }^{26} \mathrm{~N}$ ote that we exploit here the fact that the composition of consumption good and investment good demand is irrelevant for goods market equilibrium, because we assumed investment and the consumption basket to be of the same functional composite of goods.
} 
De.ning $\mathrm{K}^{\prime} \mathrm{K}_{2}=\mathrm{K}_{1}$, equation (13) may be restated in the following way:

$$
\mathrm{n}=\mathrm{K}^{ \pm}
$$

The degree of ..rm agglomeration is determined by the relative size of capital stocks. From now on, we can use ..rm agglomeration $\mathrm{n}$ and relative capital stocks $\mathrm{K}$ interchangeably. Next, the relative consumption price index $\mathrm{P}$ (real exchange rate) of the two countries can be written after some manipulations as:

$$
P=p^{\frac{3 / 4}{1 i^{3}}} ;
$$

where we used (5) and (16). De..ne relative (nominal rental rates) $r^{\prime} r_{2}=r_{1}$. Then, it follows from (11), (13) and (17) that

$$
r=p K \# 1
$$

The relative (nominal) rental rate depends on two factors: the relative capital stocks and the relative producer terms of trade. Now, we can summarize the factor and goods market equilibrium conditions in the following Lemma.

Lemma 1: For $0<K \quad 1$ holds: the correspondence $p=p(K)$ is an upward sloping function below $1 ; P=P(K)$ is a downward sloping function above $1 ; r=r(K)$ is bounded from below by $p(K)$; Finally, $\lim _{K ! 0} r(K)=1$.

Proof: See appendix 1.

Q.E.D.

Lemma 1 can be shown in ..gure 1 that depicts the terms of trade $p(K)$, relative rental rates $r(K)$, and the relative consumption price index $P(K)$ in dependence of the degree of relative capital stocks K. Note additionally that relative capital stocks $\mathrm{K}$ and ..rm agglomeration $\mathrm{n}$ are proportional (equation (17)).

Figure 1 about here

If industries are partially agglomerated in country $1(K<1)$, then the terms of trade $p(K)$ are bigger in country 1 , whereas the consumption price index $P(K)$ is smaller. 
However, the relation of rental rates $r(K)$ to relative capital stocks $K$ may be ambiguous.

These results rełect the interplay between terms of trade and agglomeration of industries that is implicit in Krugman (1991a). Suppose, the economy starts from an equal distribution of industries. Then, the relative distribution of production factors changes, because one country is accumulating more capital. Consequently, there will be more purchasing power in the larger country than in the smaller one. Because of trade costs, demand for goods of a typical ..rm is biased towards domestic ..rms. This implies that demand for goods of a typical ..rm in the larger country exceeds the one in the smaller country. However, supply of ..rms is the same across all ..rms in the Dixit and Stiglitz (1977) framework (see equation (12)). Thus, goods market clearing requires that relative producer prices fall in the smaller country. The price movement induces the exit of ..rms in the smaller country and the entry of new ..rms in the larger (see equation (17)).

The consumption price index of a typical consumer in the large country is below the one in the small country, although (factory gate) producer prices are higher in the large country and a larger share of income is spent on domestic goods (See equation (18)). This is so, because less goods have to be imported in the large country. Hence, there are less goods a transport-cost mark-up has to be paid for. (See equation (8)). In this sense, transport cost drive a wedge between relative (factory gate) producer prices and relative consumption price indices.

The ambiguous impact of the distribution of the capital stock on rental rates arises from a convergence force, i.e. capital substitutability, and from an agglomeration force, i.e. the terms-of-trade exect due to the agglomeration of manufacturing industries. The rise in the capital-labour ratio will lower the rental rate relative to the wage rate in the country with more capital; the rise in industrial agglomeration rises the terms of trade in the bigger country and rises the overall factor payments in factor market equilibrium including - in particular - rental rates (see equation (19)). 
We close the model by combining the goods and factor market equilibrium conditions and the conditions from ..rm optimization with the dynamical equations from consumer optimization. Note that the intertemporal budget constraint (6) can be reformulated to yield

$$
K_{j}^{d}=\frac{n_{j} p_{j}}{P_{j}} ; \quad C_{j}=\frac{r_{j} K_{j}}{ \pm P_{j}} ; \quad C_{j} ;
$$

where equation (12) is used and the second equality sign follows from equation (11). We note from (5), (11), (12), and (13), and Lemma 1 that the real rental rate of capital in a country depends on the level of the two capital stocks in the two countries $K_{1}$ and $K_{2}\left(1 / \frac{1}{3} r_{j}=P_{j}=1 / 3\left(K_{1} ; K_{2}\right)\right)$. Then the model may be summarized in the following 4-dimensional, non-linear dixerential equation system with the control variables $C_{1}$ and $\mathrm{C}_{2}$; the state variables $\mathrm{K}_{1}$ and $\mathrm{K}_{2}$, the national budget constraints (20), and the Euler equations (7):

$$
\begin{aligned}
& \dot{K}_{1}=\frac{1 / 3\left(K_{1} ; K_{2}\right)}{ \pm} K_{1} i C_{1} \\
& \dot{\mathrm{C}}_{1}=\left(1 / 2\left(\mathrm{~K}_{1} ; \mathrm{K}_{2}\right) \mathrm{i},\right) \mathrm{C}_{1} \\
& \dot{K}_{2}=\frac{1 / z\left(K_{1} ; K_{2}\right)}{ \pm} K_{2} i C_{2} \\
& \dot{C}_{2}=\left(1 / 2\left(K_{1} ; K_{2}\right) ;,\right) C_{2} ;
\end{aligned}
$$

where the transversality conditions are

$$
\lim _{t !} K_{j}(t){ }_{j}{ }_{j}(t)=0
$$

with the co-state variables ${ }^{1}{ }_{j}(t)$ for $(21)$ and (23), and the initial conditions are

$$
K_{j}(0)=K_{i 0}
$$

for $\mathrm{j}=1 ; 2$.

Next, the steady states are calculated. Combining (22) and (24) requires $1 / 2^{\prime}$ $1 / 2=1 / 2=r(K)=P(K)=1$ in the steady state. First, we de. ne a benchmark value for the reciprocal transport cost proxy q, such that

$$
q^{x}, \frac{(23 / 4 i 1)( \pm 3 / 4+1 ; 3 / 4)}{ \pm \pm / 4 i(1 ; 3 / 4}:
$$


Then, we can formulate the following proposition on the equalization of real rental rates of the two countries.

Proposition 1: (i) The steady state condition $1 / 2 \mathrm{~K}$ ) $=1$ has the (trivial) symmetry solution $\bar{K}=1$, if $q>q^{n} ;$ moreover, it holds that $\frac{\left.d^{12} / 1\right)}{d K}<0$ in this case.

(ii) The steady state condition $1 / 2 K K)=1$ has the solutions $\bar{K}=f K^{x} ; 1=K^{x} ; 1 g$, if

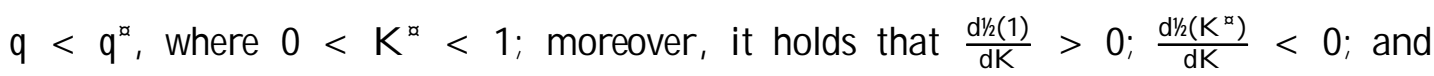
$\frac{\mathrm{d}^{\mathrm{d} /\left(21-K^{\mathrm{a}}\right)}}{\mathrm{dK}}<0$ in this case.

Proof: See appendix 2.

There are two regimes depending on the level of trade costs, and one of the two regimes expells multiple equilibria. The ..rst regime will be called neoclassical regime; the second regime will be called poverty trap regime, henceforth.

Trade costs drive a wedge between relative producer prices and consumption price indices. If this wedge widens suф ciently $\left(q<q^{a}\right)$, the intermediate solution $K^{\sharp}$ arises (see ..gure 1). In this case, an increase of the capital stock in the largest country rises the real rental rate above the one in the smallest country in the neighborhood of a symmetric distribution of capital $\left.\left(d^{1 / 2} / 1\right)=d K>0\right)$. In this sense investment projects are local complements in the poverty trap regime (spatial complementarity of investment). If the wedge between producer prices and consumption price indices is not suф ciently large $\left(q>q^{\sharp}\right)$, then an increase of the capital stock in the biggest country leads to a lower real rental rate than in the smallest country $\left.\left(d^{1} / 2 / 1\right)=d K<0\right)$. In this sense investment projects are global substitutes in the neoclassical regime (spatial substitutability of investment).

The steady state variables $\overline{\mathrm{K}}_{1} ; \overline{\mathrm{C}}_{1} ; \overline{\mathrm{K}}_{2} ; \overline{\mathrm{C}}_{2}$ can be obtained as functions of $\overline{\mathrm{K}} \cdot{ }^{27}$ However, we will not focus on their values. For future reference, we will denote the set of steady state vectors $\bar{X}^{\prime}\left(\overline{\mathrm{K}}_{1} ; \overline{\mathrm{C}}_{1} ; \overline{\mathrm{K}}_{2} ; \overline{\mathrm{C}}_{2}\right)$ and the particular steady state vectors

\footnotetext{
${ }^{27} \mathrm{~B}$ ars denote steady state values of a variable. Caveat: $\overline{\mathrm{K}}$ denotes the set of all steady state capital stocks (because there are multiple equilibria), whereas $K^{\not}$ denotes a certain value for one

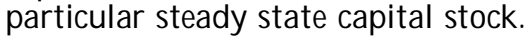




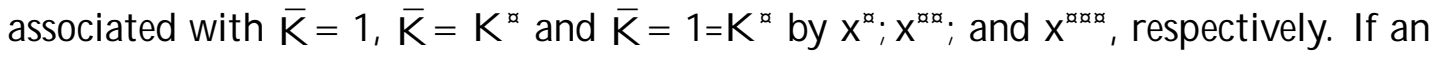
equation holds for any steady state vector, we will also use the notation $\bar{x}$.

Finally, we shall point at two interesting properties of the model. First, the model relies on constant factor shares which is one of the stylised facts of growth theory ( $K$ aldor, 1963). Second, the aggregated industry production function $n_{j} x_{j}=K_{j} 亡_{j}^{l_{i}} \pm$ exhibits constant returns to scale. Hence, the increasing returns to scale assumption on plant level is in line with empirical evidence on the production technology on industry level such as Burnside (1996).

\section{Stability A nalysis}

We will not follow the standard procedure of a local stability analysis as in Dockner (1985) for 4-dimensional, non-linear dixerential equation systems, because the J acobian of the linnearized system cannot be signed unambiguously. Instead, we will ..nd a ..rst-order approximation function for the system (21)-(24) that has (i) the same steady state values, (ii) the same J acobian matrix at the steady state values, and (iii) the J acobian matrix is unambiguously signed for any single entry. F inally, we use the fact that the qualitative behaviour of the approximation system is equivalent to the original system.

We take the dixerence in the growth rates of the capital stocks and consumption using (21)-(24).

$$
\begin{aligned}
& \frac{K_{2}}{K_{2}} ; \frac{K_{1}^{C}}{K_{1}}=\frac{1}{ \pm}\left(1 / 2\left(K_{1} ; K_{2}\right) ; \frac{1 / 3}{2}\left(K_{1} ; K_{2}\right)\right) i \frac{C_{2}}{K_{2}}+\frac{C_{1}}{K_{1}} \\
& \frac{C_{2}}{C_{2}} ; \frac{C_{1}}{C_{1}}=1 / 2\left(K_{1} ; K_{2}\right) ; 1 / \frac{1}{1}\left(K_{1} ; K_{2}\right)
\end{aligned}
$$

We would like to express these equations in terms of relative capital and consumption. For this purpose, we "guess" the following approximation function to the system (28):

$$
\frac{K^{t}}{K}=\frac{a_{1}}{ \pm} \ln 1 / 2(K) ; \quad a_{2} \ln C+a_{2} \ln K
$$




$$
\frac{\stackrel{c}{C}}{C}=a_{1} \ln 1 / 2(K) ;
$$

where we de..ned $C^{\prime} \quad C_{2}=C_{1}, a_{1}{ }^{\prime} t / 2$, and $a_{2}{ }^{\prime} \bar{C}_{2}=\bar{K}_{2}$. This approximation is entirely suф cient to describe the behaviour of the terms of trade around the steady state and to pin down the relation of all state variables (capital, income, and ..rm distribution) between the two countries around the steady state values. ${ }^{28}$ However, for the approximation to be valid, we need to show that the approximation (29) is chosen such that this system has the same steady states and the same qualitative dynamic behaviour as the original system (28). The ..rst property is easily con..rmed, whereas the second is proven in Lemma 2.

Lemma 2: The J acobian matrix of the dynamical system (29), (21), and (22) evaluated at any of the steady states has the same eigenvalues as the J acobian matrix of the dynamical system (21)-(24).

P roof: See appendix 3.

Q.E.D.

This lemma will be used for the local stability analysis that is summarized in the next proposition.

Proposition 2: Consider the dynamical system (21)-(26). A ssume that the eigenvalues are distinct. Then, this system is locally asymptotically stable if either

$$
\begin{aligned}
& \text { (i) } q>q^{\natural} \text { and } \bar{K}=1 \text { or } \\
& \text { (ii) } q<q^{\alpha} \text { and } \bar{K}=K K^{\ltimes} \text { or }
\end{aligned}
$$$$
\text { (iii) } \quad q<q^{\sharp} \text { and } \bar{K}=1=K^{\natural} \text {. }
$$

Furthermore, there exist three corresponding two-dimensional local stable manifolds

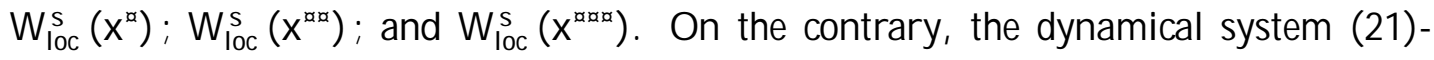
(26) has a one-dimensional local stable manifold $W_{\text {loc }}^{\mathrm{s}}\left(x^{\natural}\right)$, if

\footnotetext{
${ }^{28}$ To recover the absolute values of the state variables, two more equations are necessary: e.g. the dynamical equations governing country 1 . We skip them to focus on the idea of the solution method, but use them in the rigorous mathematical derivation in Lemma 2 and appendix 3.
} 

$q<q^{\natural}$ and $\bar{K}=1$.

This local stable manifold is described by $K_{1}(t)=K_{2}(t)$ and $C_{1}(t)=C_{2}(t)$ for 0 t 1 .

Proof: See appendix 4.

Proposition 2 resembles a supercritical pitchfork bifurcation with the bifurcation parameter $q$ and the bifurcation point $q=q^{a}$ : We illustrate this in the following bifurcation diagram.

\section{Figure 2 about here}

The vertical axes shows the position of steady state equilibria in terms of the relative distribution of capital; the horizontal axes shows the level of trade costs. At a high level of trade costs (low q), there are three steady states with the symmetric one $(\bar{K}=1)$ being unstable (poverty trap regime). At a low level of trade costs (high q), there is only one stable steady state equilibrium at a symmetric distribution of capital (neoclassical regime).

The poverty trap regime emerges if and only if investment projects become locally complementary in the neighborhood of a symmetric distribution of capital and ..rms. ${ }^{29}$ A round a symmetric distribution of capital, an increase of investment in one country relative to the other increases, rather than decreases, the relative real marginal productivity of capital in terms of the consumer price indices inducing more investment to take place in the former than in the latter country. At some degree of divergence in capital stocks and ..rm distribution the divergence process stops, because investment projects have become locally substitutes. A further rise of investment in the booming country lowers the real marginal productivity of capital relative to the declining country. Therefore the divergence process remains incomplete and a certain asymmetric distribution of capital and ..rms is a stable equilibrium.

\footnotetext{
${ }^{29}$ This follows immediately from the proof of proposition 2 in appendix 4, equations (71)-(74). Note that the investment complementarity is referring to the ratio of capital stocks and the ratio of real rental rates rather than to their absolute values as in the closed economy model of Gali (1995).
} 
The neoclassical regime emerges on the contrary, if investment projects are globally substitutes, i.e. a relative rise in investment of one country above investment in the other lowers the real marginal product of capital in the former relative to the latter country. Therefore, only the symmetric distribution of capital can be a stable steady state. Given that there can exist multiple stable local manifolds, it is important to examine one aspect of global stability.

Proposition 3: Consider the dynamical system (21)-(26) and the case $q<q^{\sharp}$ : For any given combination of initial conditions $\mathrm{K}_{10} ; \mathrm{K}_{20} 2 \mathrm{R}^{+}$, there exists a unique perfect foresight path for the two control variables $C_{1}$ and $C_{2}$. Furthermore, $x^{\sharp}$ is reached, if $\mathrm{K}_{10}=\mathrm{K}_{20} ; \mathrm{x}^{\mathrm{ax}}$ is reached, if $\mathrm{K}_{10}>\mathrm{K}_{20} ; \mathrm{x}^{\mathrm{xdx}}$ is reached, if $\mathrm{K}_{10}<\mathrm{K}_{20}$;

Proof: See appendix 5.

Q.E.D.

This proposition ensures that there exists a unique perfect foresight path. Only one of the three steady states can be reached for any given combination of initial conditions. Therefore, this model does not exhibit expectations driven agglomeration processes as have been found in other dynamic models with increasing returns to scale like Matsuyama (1991), Krugman (1991b), and Kaneda (1995). In particular, we do not need any additional coordination mechanism of expectations as K aneda's (1995) assumption of "euphoric expectations" to select among multiple perfect foresight path.

\subsection{The Neoclassical Growth Regime}

In this section we discuss in detail the neoclassical regime, i.e. the case where trade costs are relatively low $\left(q>q^{x}\right)$. Recall that there is one steady state distribution of capital $\bar{K}=1$. We summarize our results:

Result 1: The neoclassical regime $\left(q>q^{\alpha}\right)$ exhibits outphasing growth and convergence of income. ${ }^{30}$

The dynamic adjustment path is shown in ..gure 3.

\footnotetext{
${ }^{30} \mathrm{~T}$ his follows from proposition 2: the steady state is stable and the relative capital stock approaches one. However, income is a monotone, increasing function of the capital stock.
} 
Figure 3 about here

The ..gure presents the unique stable manifold of the 4 dimensional dixerential equation system (21)-(26). In particular, there is a unique mapping from the state space $\mathrm{K}_{2} \mathrm{i} \mathrm{K}_{1}$ to the control variable space $\mathrm{C}_{2} ; \mathrm{C}_{1}$ which follows from the stable manifold theorem (see proposition 2). Even if two structurally identical countries start out with dissimilar capital stocks, i.e. one country is poor and the other is rich, there will be convergence of capital stocks and per capita income. The poorer country will grow faster than the richer country in the transition period to the steady state.

Our neoclassical growth regime dixers from, e.g., a Solow or a Ramsey model (without technological progress and population growth) by a dixerent adjustment path. Thus, countries that catch-up do not follow the same path as the leading countries. History does not repeat, as is the case in the Solow and Ramsey model. Once some country is ahead, the catch-up process will change terms of trade and the real marginal product of capital. This will foster income growth of the country lacking behind beyond what is predicted by a model with two isolated Ramsey economies. In this sense, the speed of convergence is higher in our neoclassical regime than in the isolated Ramsey economies.

E mpirically, it is hard to "detect" the terms-of-trade exect caused by an investment boom, because any terms-of-trade exect due to total factor productivity growth (which is excluded in our model) has to be controlled for. Note that in our model the country that is growing fastest improves its terms of trade, because the home market exect together with trade costs causes a demand bias towards domestic goods at a given supply. If total factor productivity growth were the reason for dixerent growth rates, then the faster growing economy is deteriorating its terms of trade, because a rise in total factor productivity rises output and decreases its relative price. ${ }^{31}$ In a complementary study, Urban (1998) tests the terms-of-trade exect for the US and

\footnotetext{
${ }^{31}$ T his is, for example, the case in Osang and Pereira (1997) which is a two-country, human capital driven endogenous growth model with two sectors, balanced trade, and complete specialization.
} 
J apan from 1957 until 1990 and ..nds weak evidence in favour of our model during the $\ddagger$ exible exchange rate regime after Bretton-Woods using cointegration techniques. ${ }^{32}$

Furthermore, our model predicts that trade-liberalization triggers a convergence process eliminating poverty traps, if q passes the threshold $q^{\text {a. }}$. This adds qualitatively a new dimension to the relation between trade openness and growth as described by dynamic el ciency gains (Baldwin, 1992, and Baldwin and Seghezza, 1996). The bifurcation property of trade openness is in line with the ..nding of Ben-David (1993) who shows: 1) There is absolute convergence of income in an economy with trade liberalization (EEC6 ${ }^{33}$ from 1959-1968, EE C $3^{34}$ after the mid-sixties, USA and Canada after the K ennedy Round Agreement), or with trade and factor market integration (the convergence of the US states). 2) There is no absolute convergence of economies that are not integrated (e.g. the EEC 6 and the EEC3 before trade liberalization, the 25 most developed countries, or the "whole world"). ${ }^{35}$ Therefore, this evidence points to a two regime scenario with trade liberalization being the bifurcation parameter as suggested by our model. ${ }^{36}$

Next, our model explains the catch-up process by increased capital accumulation that is triggered by trade liberalization. It has been noted by Young (1995) that factor accumulation rather than total factor productivity growth explains the East

\footnotetext{
${ }^{32} \mathrm{~A}$ positive relation between GDP and international price levels can also be inferred from the cross-country price data of Summers and Heston (1991). B arro and Sala-i-M artin (1995) show that GDP growth and terms of trade are positively correlated. (Note that the original estimates in Barro and Lee, 1994, are revised.) Because Barro and Sala-i-M artin (1995) try to capture all structural characteristics of the economies, we may take this as weak evidence that not dixerences in structural characteristics that may inłuence total factor productivity explain the impact of terms of trade on growth. However, the estimates of Barro and Sala-i Martin (1995) may fail the robustness test of Levine and Renelt (1992).

${ }^{33} \mathrm{~T}$ his is the group of countries consisting of France, West Germany, Belgium, the Netherlands, Luxembourg, and Italy.

${ }^{34} \mathrm{~T}$ his is the group of countries consisting of Denmark, Ireland, and UK.

35 If there is conditional convergence among the EEC6 (Barro and Sala-i-Martin, 1992), but not absolute convergence, then factors other than capital accumulation must drive income convergence. If trade liberalization causes absolute convergence, then trade liberalization must have caused a catch-up in capital stocks. This is the transmission channel in our model.

${ }^{36} \mathrm{~T}$ he role of trade openness as bifurcation parameter may be reversed, if dixerent convergence forces are chosen (see section 5.3). Rauch (1997) gives the examples of Chile 1974-79 and of Italy's political uni..cation 1861, and explains the subsequent economic slumps in an endogenous growth model.

In the relation of trade liberalization and growth, our model deviates in spirit from M yrdal (1957). "T he hampering of industrial growth in the poorer southern provinces of Italy, caused by the pulling down of internal tariø walls after Italy's political uni..cation in the last century, is a case in point which has been thoroughly studied ..." (p. 28)
} 
Asian growth miracles. Furthermore, Levine and Renelt (1992) show that the impact of openness on growth stems from investment promotion, not from productivity growth. Finally, Moreno and Trehan (1997) ..nd an empirical link between market size and investment supporting the theoretical link between home-market exect and capital accumulation of our model.

\subsection{The Poverty Trap R egime}

In this section we discuss in detail the poverty-trap regime, i.e. the case where trade costs are relatively high $\left(q<q^{\mathrm{d}}\right)$. Recall that there are three steady state distributions of capital, one of which is unstable. We summarize our results:

Result 2: In the poverty trap regime $\left(q<q^{\sharp}\right)$, income levels tend to diverge monotonically up to some relative ratio $Y^{\sharp}=K^{\sharp \pm}$, if country 2 is taken to be the smaller country. ${ }^{37}$

The poverty trap case is graphically exposed in ..gure 4 which is drawn in line with propositions 2 and 3. The ..gure shows the map of the state space (initial capital distribution) on the control variable space (consumption choices) belonging to the three local stable manifolds $\mathrm{W}_{\text {loc }}^{\mathrm{s}}\left(\mathrm{X}^{\natural}\right) ; \mathrm{W}_{\text {loc }}^{\mathrm{s}}\left(\mathrm{x}^{\mathrm{g}}\right)$; and $\mathrm{W}_{\text {loc }}^{\mathrm{s}}\left(\mathrm{x}^{\mathrm{gn}}\right)$ which are related to the three steady-state vectors $x^{\sharp} ; x^{n z}$, and $x^{\text {and }}$, respectively.

Figure 4 about here

Proposition 3 ensures that, for $\mathrm{K}_{1}(0)=\mathrm{K}_{2}(0)$; consumption is chosen in line with the stable manifold $\mathrm{W}_{\text {loc }}^{\mathrm{s}}\left(\mathrm{x}^{\mathbb{q}}\right)$ that leads to the symmetric steady state $\mathrm{X}^{\sharp}$; if $\mathrm{K}_{1}(0)>$ $\mathrm{K}_{2}(0)$; consumption is chosen in line with the stable manifold $\mathrm{W}_{\text {loc }}^{\mathrm{S}}\left(\mathrm{X}^{\mathrm{B}}\right)$ that leads to the steady state $x^{\text {ar }}$ with more capital in country 1 ; if $K_{1}(0)<K_{2}(0)$; consumption is chosen in line with the stable manifold $W_{\text {loc }}^{S}\left(x^{\text {मnd }}\right)$ that leads to the steady state $X^{\text {and }}$ with more capital in country 2. Because $\mathrm{W}_{\text {loc }}^{\mathrm{s}}\left(\mathrm{x}^{\natural}\right)$ is one-dimensional, any slight disturbance of this symmetric growth path, in the sense that one country accumulates

\footnotetext{
${ }^{37} T$ he statement follows from proposition 2 that shows the divergence of the capital stocks and from the fact that national income is a monotonic function of capital.
} 
more capital at some time period (idiosyncratic shock), will leave the symmetric steady state unachievable. Capital stocks and income will diverge governed by one of the other two stable manifolds depending on which country received a positive or negative idiosyncratic shock. ${ }^{38}$

Our model can be distinguished from most of the poverty trap models in a growth setting by explaining income divergence of two countries even though initial conditions are the same except for an idiosyncratic shock. In other words, the ratio of initial conditions matters, not the initial conditions themselves. This has two implications. First, poverty trap models where absolute values of initial conditions matter ${ }^{39}$ have dic culties explaining how the rich countries left the poverty trap, whereas the poor countries did not, if all countries started from roughly the same income levels, say in the 17 th/ 18 th century. ${ }^{40}$ Our model allows some countries to become rich, and others, that are hit by some negative idiosyncratic shock, stay poor. Second, our model is especially suited for explaining the fall-back of highly developed countries like the $\mathrm{U}$ nited Kingdom and Argentina after the turn of the century relative to countries that had initially the same state of development. ${ }^{41}$ A wide range of "leapfrogging" models exist that are often based on endogenous growth settings. ${ }^{42}$ We show that a neoclassical growth setting can also account for the fall-back of nations, if they are hit by some suф ciently large exogenous shock. There is still one observation to be made concerning the terms of trade.

R esult 3: In the poverty trap regime $\left(q<q^{a}\right)$, there is a worsening of the terms of trade $p(t)$ over time in the country that lags behind vis a vis the country that is ahead,

\footnotetext{
${ }^{38}$ We cannot accomplish a global dynamic analysis, but numerical simulations suggest that a typical divergence path would stay close to the symmetric growth path for a long time after an idiosyncratic shock has occured and will eventually lead to a drastic relative and absolute decline in the country that was originally hit.

${ }^{39} \mathrm{~T}$ hese are the poverty trap models corresponding to the club convergence hypothesis. A de..nition and an overview of convergence hypotheses is given by Galor (1996).

${ }^{40 \text { " T }}$ he very fact that the world at present is so sharply divided between 'rich' and 'poor' countries is, in the context of the broad sweep of history, something relatively new: it is the cumulative result of the historical experience of two or three hundred years. If we go back a few hundred years for example, to 1700 or 1750, we do not ..nd, as far as we can tell, such large dixerences in real income per capita between dixerent countries or regions." K aldor (1967, p.3)

${ }^{41}$ We may then interpretate the idiosyncratic shock as political turmoil, unfavourable price movements of primary products, and import substitution policy in the case of Argentina and as the loss of colonies in the case of the U nited Kingdom.

${ }^{42} \mathrm{~A} n$ example is Grossman and Helpman (1991).
} 
where terms of trade are de..ned in fob-manufacturing-producer prices. ${ }^{43}$

There has been an extensive discussion in the 50ies, whether developing countries faced a persistent worsening of their terms of trade from 1870 til $1938 .{ }^{44}$ Although - strictly speaking - our model is only suitable to developing countries whose export goods are produced with increasing returns to scale and monopolistic competition ${ }^{45}$, our model suggests that a worsening of the terms of trade was in principle explicable, whenever investment projects were locally complements and capital accumulation was poor. ${ }^{46}$ Our model suggests that the appropriate policy meassure was not to close national markets (import substitution) despite that trade seemed to harm developing countries, but to open national markets in order to eliminate the underlying poverty trap - a recommendation that ..nds broad consensus nowadays.

\subsection{E conomic G eography}

Having shown the interdependence between real marginal product of capital, capital accumulation, and terms of trade, we focus now on the aspect of agglomeration of manufacturing industries. From the analysis so far it follows immediately (by equation (17)) that the faster growth in the country with more capital causes a larger number of ..rms which we take as a proxy for manufacturing industry agglomeration. A relative increase in domestic capital increases domestic income, which in turn increases demand for any existing domestic variety. The latter increases domestic producer prices relative to foreign (terms-of-trade exect), which leads to positive pro..ts of domestic ..rms and thus the entry of new domestic ...rms.

\footnotetext{
${ }^{43}$ Suppose country 2 lacks behind. From proposition 2 follows that the relative capital stock $\mathrm{K}$ (t) approaches assymptotically $K^{\nwarrow}<1$. From numerical simulations can be inferred that $K(t)$ changes monotonically. From Lemma 1 follows that $p(t)$ is monotonically increasing with $K(t)$. Therefore, the time path for $p(t)$ has the same qualitative properties as the time path for $K(t)$ :

${ }^{44}$ A $n$ empirical survey is Spraos (1980).

${ }^{45}$ Spraos (1980) indicates: "Perhaps more important than any of these is the processing of primary products before shipment (for instance, cocoa beans turned into cocoa butter and cocoa paste) which has been increasing all the time, though in developing countries it had gained great momentum only in the last twenty years." (p. 118) Additionally, mining and agro-business may not a priori be less likely described by increasing returns to scale than manufacturing industries.

${ }^{46}$ Of course, we do not doubt that other explanations can be found. We just want to point out that the terms of trade exect in our poverty trap regime does not run counter to the empirical literature.
} 
Result 4: At high trade costs $\left(q<q^{\sharp}\right)$, there will be partial agglomeration of manufacturing industries in one country. ${ }^{47}$

Hence, a low growth rate is associated with a decline of manufacturing industries. Indeed, slower growth and a decline of manufacturing industries self-enforce each other in a cumulative process. Conversely, agglomeration of manufacturing industries is explained by faster capital accumulation in one country relative to another. This explanation dixers from other explanations in papers on agglomeration and growth - as Bertola (1992), Englmann and Walz (1995), and Martin and Ottaviano (1996). In these papers, agglomeration processes in growth models rely on migration, capital łows with technological spill-overs, and R\&D location decisions.

The role of trade costs for triggering agglomeration is reversed compared to K rugman (1991a). This is so, because we exchanged the convergence forces. K rugman's (1991a) convergence force is based on ambiguous terms-of-trade exects caused by an immobile farming sector. As trade costs increase from a very low level, terms of trade increase in the larger country. (We observed the same exect in our model.) However, as trade costs increase further in K rugman (1991a), terms of trade may start to decrease. This exect is not present in our model. We conclude therefore that the role of trade costs is not robust with respect to the speci..c convergence force used in geography and trade models.

\section{Conclusion}

We argued that relative income growth and manufacturing industry distribution among countries are mutually in uencing each other. This hypothesis has been formulated by M yrdal (1957) and Kaldor (1967). They argue that a cumulative process may keep some countries poor and others rich, because an expansion process (decline) may rise (lower) the return on investment in the expanding (declining) country thus causing further expansion (contraction) by capital accumulation. The empirical convergence

\footnotetext{
${ }^{47} \mathrm{~T}$ his follows from result 2 and from equation (17).
} 
debate suggests, however, that income divergence is a possible, but not a general phenomenon. Therefore, we built a model that explains income divergence in a poverty trap regime, income convergence in a neoclassical regime, and a testable condition under which a country is in one or the other regime. This condition depends on the degree of integration in product markets. If trade barriers are high, income divergence is likely to occur. If trade barriers are low, income convergence is the unique equilibrium. Thus, trade liberalization may trigger a catch-up process of countries that are stuck in a poverty trap.

The interrelation of growth and agglomeration is described by circular causation. Countries grow faster (slower), because they have a lot of (a few) manufacturing industries. Countries have a lot of (a few) manufacturing industries, because they have grown faster (slower) in the past and thereby accumulated more (less) capital. The circular causation relies on a terms-of-trade exect that may or may not feed through on real rental rates (spatial complementarity or substitutability of investment). The countries stuck in the poverty trap experience slower growth, a lower investmentto-GDP ratio, a worsening of their terms of trade, and a decline in manufacturing industries. The countries that catch-up experience a higher growth rate, a higher investment-to-GDP ratio, an improvement of their terms of trade, and manufacturing industries dixuse to the poor country.

The results in this paper have been derived in a speci..c model set-up - increasing returns, and monopolistic competition. Following the same sort of argument as Gali (1994) for a closed economy, the pitchfork-bifurcation property may also appear in a set-up with Cournot oligopoly. Our analysis shows that divergence of income and ..rm agglomeration emerge, whenever investment projects are complementary in the neighborhood of a symmetric distribution of capital and ..rms. 


\section{References}

A bdel-Rahman, H.M., (1988), Product dixerentiation, monopolistic competition and city size, R egional Science and U rban Economics, Vol. 18, p. 69-86.

d'A spremont, Claude, Rudolphe Dos Santos Ferreira, and Louis-A ndré Gérard-Varet, (1996), On the Dixit-Stiglitz Model of Monopolistic Competition, A merican Economic R eview, Vol. 86, p. 623-629.

A zariadis, Costas, (1996), The economics of poverty traps - part one: Complete markets, J ournal of E conomic Growth, Vol. 1, p. 449-487.

Baldwin, Richard E., (1992), M eassurable dynamic gains from trade, J ournal of Political Economy, Vol. 100, p. 162-174.

Baldwin, Richard E., (1998), A gglomeration and endogenous capital, CEPR Discussion Paper, No. 1845.

Baldwin, Richard E., and Rikard Forslid, (1997), The core-periphery model and endogenous growth, CEPR Discussion Paper, No. 1749.

Baldwin, Richard E., and Rikard Forslid, (1998), Incremental trade policy and endogenous growth: A q-theory approach, NBER Working Paper, No. 6477.

Baldwin, Richard E., Rikard Forslid and J an I. Haaland, (1995), Investment creation, and investment diversion: simulation analysis of the single market programme, Discussion Paper Norwegian School of Economics and Business Administration, No. 23/95.

Baldwin, Richard E., Philippe Martin, and Gianmarco I. P. Ottaviano, (1998), Global income divergence, trade, and industrialization: The geography of growth takeoxs, NBER Working Paper, No. 6458.

Baldwin, Richard E., and E lena Seghezza, (1996), Trade-induced investment-led growth, CEPR Discussion Paper, No. 1420.

Barro, Robert J ., (1991), E conomic growth in a cross section of countries, Quarterly J ournal of Economics, Vol. 106, p. 407-443.

Barro, Robert J ., and J ong-W ha Lee, (1994), Sources of economic growth, CarnegieRochester Conference Series on P ublic Policy, Vol. 40, p. 1-46.

Barro, R obert J ., and X avier Sala-i-M artin, (1992), Convergence, J ournal of Political Economy, Vol. 100, p. 223-251.

Barro, Robert J ., and Xavier Sala-i-M artin, (1995), E conomic Growth, M cGraw-Hill, New York.

Baumol, W illiam J ., Sue A nn Batey B lackman, and Edward N. Wolæ, (1989), Productivity and A merican leadership: The long view, MIT Press, Cambridge MA.

Ben-David, Danny, (1993), Equalizing exchange: Trade liberalization and income convergence, Quarterly J ournal of Economics, Vol. 108, p. 653-79.

Ben-David, Danny, and Michael B. Loewy, (1998), Free trade, growth, and convergence, J ournal of Economic growth, Vol. 3, p. 143-170.

Bertola, Guiseppe, (1992), Models of economic integration and localized growth, CEPR Discussion Paper, No. 651.

Brock, W.A., and A.G. Malliaris, (1989), Dixerential equations, stability and chaos in dynamic economics, North-Holland, A msterdam.

Buiter, W illem (1984), Saddle point problems in continuous-time rational expectations 
models: a general method and some macroeconomic examples, E conometrica, Vol. 52, p. 665-680.

Burnside, Craig, (1996), Production function regressions, returns to scale, and externalities, J ournal of M onetary Economics, Vol. 37, p. 177-201.

Caselli, Francesco, Gerardo Esquivel, and Fernando Lefort, (1996), Reopening the convergence debate: A new look at cross-country growth empirics, J ournal of Economic Growth, Vol. 1, p. 363-389.

Cohen, Daniel, (1996), Tests of the "convergence hypothesis": Some further results, J ournal of Economic Growth, Vol. 1, p. 351-361.

Dixit, A vinash K., and J oseph E. Stiglitz, (1977), M onopolistic competition and optimum product diversity, A merican Economic R eview, Vol. 67, p. 297-308.

Dockner, Engelbert, (1985), Local stability analysis in optimal control problems with two state variables, in: Gert Feichtinger, ed., Optimal control theory and economic analysis 2, North Holland, A msterdam.

Durlauf, Steven N., and Paul A. J ohnson, (1995), Multiple regimes and cross-country growth behaviour, J ournal of A pplied Econometrics, Vol. 10, p. 365-384.

Englmann, Frank-C., and U we Walz, (1995), Industrial centers and regional growth in the presence of local inputs, J ournal of R egional Science, Vol. 35, p. 3-27.

Fujita, Masahisa, (1988), A monopolistic competition model of spatial agglomeration, Regional Science and U rban Economics, Vol. 18, p. 87-124.

Fujita, Masahisa and J acque Francois Thisse, (1996), Economics of agglomeration, CEPR Discussion Paper, No. 1344.

Galí, J ordi, (1994), Monopolistic competition, endogenous mark-ups, and growth, European Economic R eview, Vol. 38, p. 748-756.

Galí, J ordi, (1995), Product diversity, endogenous mark-ups, and development traps, J ournal of M onetary Economics, Vol. 36, p. 39-63.

Galor, Oded, (1996), Convergence? Inferences from theoretical models, Economic J ournal, Vol. 106, p. 1056-1069.

Grossman, Gene M., and Elhanan Helpman, (1991), Innovation and growth in the global economy, MIT Press, Cambridge MA.

J ones, Charles I., (1995), T ime series tests of endogenous growth models, Quarterly J ournal of Economics, Vol. 110, p. 495-526.

J ones, Charles I., (1997), Convergence revisited, J ournal of Economic Growth, Vol. 2, p. 131-153.

Kaldor, Nicholas, (1963), Capital accumulation and economic growth, in: Friedrich A. Lutz and Douglas C. Hague, eds., Proceedings of a conference held by the international economics association, Macmillan, London.

K aldor, Nicholas, (1967), Strategic factors in economic development, T he Frank Pierce Memorial Lectures at Cornell University, W.F. Humphrey Press, Geneva.

Kaneda, Mitsuhiro, (1995), Industrialization under perfect foresight: a world economy with a continuum of countries, J ournal of Economic Theory, Vol. 66, p. 437-462.

K elly, M organ, (1997), The dynamics of Smithian growth, Quarterly J ournal of Economics, Vol. 112, p. 939-964.

K rugman, Paul R ., (1991a), Increasing returns and economic geography, J ournal of 
Political Economy, Vol. 99, p. 483-499.

K rugman, Paul R., (1991b), History versus expectations, Quarterly J ournal of Economics, Vol. 106, p. 651-667.

K rugman, Paul R., and A nthony J. Venables (1995), Globalization and the inequality of nations, Quarterly J ournal of Economics, Vol. 110, p. 857-880.

Levine, Ross and David Renelt, (1992), A sensitivity analysis of cross-country growth regressions, A merican Economic R eview, Vol. 82, p. 942-963.

Lucas, Robert E., J r., (1988), On the mechanics of development planning, J ournal of Monetary Economics, Vol. 22, p. 3-42.

Mankiw, Gregory N., David Romer, and David N. Weil, (1992), A contribution to the empirics of economic growth, Quarterly J ournal of Economics, Vol. 107, p. 407-37.

Martin, Philippe, and Gianmarco I. P. Ottaviano, (1996), Growth and agglomeration, mimeo.

M atsuyama, Kiminori, (1991), Increasing returns, industrialization and indeterminacy of equilibria, Quarterly J ournal of Economics, Vol. 106, p. 617-650.

Moreno, Ramon, and Bharat Trehan, (1997), Location and the growth of nations, J ournal of Economic Growth, Vol. 2, p. 399-418.

Murphy, Kevin M., A ndrei Shleifer, and Robert W. Vishny, (1989), Industrialization and big push, J ournal of Political Economy, Vol. 97, No. 5, p. 1003-1026.

Myrdal, Gunnar, (1957), Economic theory and under-developed regions, Duckworth, London.

Osang, Thomas, and Alfredo Pereira, (1997), Savings, volume of trade, and growth, Review of International Economics, Vol. 5, No. 3, p. 310-323.

Quah, Danny T., (1997), Empirics for growth and distribution: Strati..cation, polarization, and convergence clubs, J ournal of Economic Growth, Vol. 2, p. 27-59.

Quah, Danny T., (1993), Galton's fallacy and tests of the convergence hypothesis, The Scandinavien J ournal of Economics, Vol. 95, No. 4, p. 427-443.

Rauch, J ames E., (1997), Balanced and unbalanced growth, J ournal of Development Economics, Vol. 53, p. 41-66.

Rivera-Batiz, Francisco L., (1988), Increasing returns, monopolistic competition, and agglomeration economies in consumption and production, R egional Science and Urban Economics, Vol. 18, p. 125-153.

Solow, R obert M. (1956), A contribution to the theory of economic growth, Quarterly J ournal of Economics, Vol. 70, p. 65-94.

Spraos, J ohn, (1980), The statistical debate on the net barter terms of trade between primary commodities and manufactures, The Economic J ournal, Vol. 90, p. 107-128.

Summers, Robert, and Alan Heston, (1991), The Penn World Table (Mark 5): An expanded set of international comparisons, 1950-1988, Quarterly J ournal of Economics, Vol. 106, p. 327-368.

Stiglitz, J oseph E. (1970), Factor price equalization in a dynamic economy, J ournal of Political Economy, Vol. 78, p. 456-488.

Urban, Dieter M., (1998), Convergence, terms of trade, and cointegration: The example J apan, mimeo. 
Venables, Anthony J., (1996), Equilibrium locations of vertically linked industries, International Economic Review, Vol. 37, p. 341-359.

Young, A Iwyn (1995), The tyranny of numbers: Confronting the statistical realities of the East A sian growth experience, Quarterly J ournal of E conomics, Vol. 110 , p. $641-680$. 


\section{Appendix}

A ppendix 1: Proof of Lemma 1.

Taking the derivative of (16) yields:

$$
\frac{d n}{d p}=\frac{i^{3 / 4} p^{3 / 4}\left(q_{i} p^{3 / 4}\right) i\left(q_{i} p^{3 / 4}\right)\left(q_{i}\left(1 ; 3 / 4 p^{3 / 4}\right)\right.}{p^{2}\left(q_{i} p^{3 / 4}\right)^{2}}
$$

with $0<n<1$ : (a) Suppose $p>1$, then $q_{i} p^{3 / 4}<0$. Therefore, $q_{i} p^{i / 4}<0$ for $n$ to be positive by inspection of (16). Then follows by inspection of (30) that $d n=d p>0$, because $3 / 4>1$ by assumption. (b) Suppose $p<1$, then $q_{i} p^{i / 4}<0$. Therefore, $q_{i} p^{3 / 4}<0$ for $n$ to be positive by inspection of (16). Then follows by inspection of (30) that $d n=d p>0$, because $3 / 4>1$ by assumption. This implies that the invers function $\mathrm{p}$ ! $\mathrm{n}$ exists in the positive range. From (17) follows that $\mathrm{K}$ and $\mathrm{n}$ are proportional. Hence, we have that $p(K)$ is an invertible function and $d p=d K>0$. $P(K)$ must then be downward sloping from (18). From (19) follows that $r(K)$ is bounded from below by $p(K)$. Finally, the limit with respect to complete agglomeration $(K ! 0)$ can be taken from (19).

Q.E.D.

A ppendix 2: Proof of Proposition 1.

We will ..rst show that there are at most 3 solutions to $1 / 2(K)^{\prime} \quad r(K)=P(K)=1$. Using equations (18) and (19) yields:

$$
r=P=p n^{ \pm 1} \frac{1}{ \pm} p^{\frac{3 / 4}{1 i^{3 / 4}}}=1:
$$

Plugging in the goods market equilibrium condition (16) yields:

$$
p^{\frac{1}{1_{i} i^{3 / 4}}}{\frac{q_{i} p^{3 / 4}}{p\left(q_{i} p^{3 / 4}\right)}}^{\prod_{ \pm}^{ \pm \pm 1}}=1:
$$

Multiplying out gives a power function of the form:

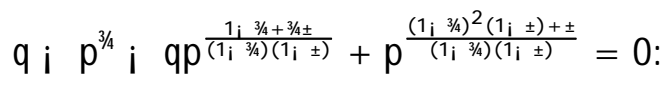

This expression has at most 3 solutions for $p$ due to Descartes' R ule of Sign. Because there is a one-to-one mapping from $\mathrm{p}$ to $\mathrm{n}$ to $\mathrm{K}$ (Lemma 1 ), there correspond at most three values for $n$ and $K$. We conclude: one solution is $K=1$ ( $T$ he symmetry solution is always true.); if there exists a second solution $K^{x}<1$, then the third must be $\left(1=K^{x}\right)>1$ because of the symmetry of the model.

Now, we will give a necessary and su $₫$ cient condition for the existence of $K$ " by restricting our view on $0<K \quad 1$. Recall from Lemma 1 : $\lim _{K !} r(K)=1$, whereas $P(0)$ is ..nite. Hence,

$$
\lim _{K ! 0} 1 / 2(K) \lim _{K ! 0} \frac{r(K)}{P(K)}>1:
$$

There will exist the interior solution $K^{*}$, if $1 / 2 K$ ) $<1$ for $K$ slightly below 1 (intermediate value theorem). This is not just a necessary condition for the existence of $K{ }^{\star}$, but also a suф cient condition for $K^{\text {" }}$ to be the only interior solution $\left(0<K^{\not}<1\right)$, because $1 / 21$ ) $=1$. (Suppose on the contrary that $K^{\prime \prime}$ exists and $1 / 2(K)>1$; when $K$ is slightly below 1 , then there will exist at least two interior solutions (or none) for $0<\mathrm{K}<1$ which contradicts our ..ndings above.) From (17) follows that there 
corresponds a $n^{\star}=K^{\star \pm}$. We can formulate the necessary and suc cient condition for an interior solution $n^{\star}$ also in the following way:

$$
\frac{\mathrm{dP}(1)}{\mathrm{dn}}<\frac{\mathrm{dr}(1)}{\mathrm{dn}}
$$

Evaluating the derivative of the relative price index yields:

$$
\frac{d P(n)}{d n}=\frac{3 / 4}{1 ; 3 / 4} \frac{d p(n)}{d n}:
$$

Evaluating this expression at $n=1$ and using equation (30) gives us:

$$
\frac{d P(1)}{d n}=\frac{3 / 4}{1 ; 3 / 41 ; ~} \frac{q_{i} 3 / 4 i}{q} \text { : }
$$

Next, the derivative of relative rental rates is found:

$$
\frac{d r(n)}{d n}=\frac{d p(n)}{d n} n^{ \pm \pm 1}+p^{\mu} \frac{ \pm i 1^{n}}{ \pm} n^{i \frac{1}{ \pm}}:
$$

We evaluate this expression at $n=1$ by using (30):

$$
\frac{\mathrm{dr}(1)}{\mathrm{dn}}=\frac{q_{\mathrm{i}} 1}{1 \mathrm{i} 23 / 4 \mathrm{i} q}+\frac{ \pm_{\mathrm{i}} 1}{ \pm}
$$

Using (37) and (39) in (35) yields an inequality

$$
\frac{q_{i} 1}{1 ; q_{i} 23 / 4} \frac{23 / 4 i}{1 / 4}<\frac{ \pm i 1}{ \pm}
$$

which can be solved for q:

$$
q<q^{\alpha}, \frac{(23 / 4 ; 1)( \pm 3 / 4+1 ; 3 / 4}{ \pm 3 / 4 i(1 ; 3 / 4}<1:
$$

A similar argumentation holds for $1=n^{\sharp}$ and $1 \quad n<1$, i.e. $1=K^{\sharp}$ and $1 \quad K<1$, by the symmetry property of the model.

Finally, the derivative in (i) follows from $1 / 2(1)=1$; $1 / 2(K)>1$, if $K<1$; and $1 / 2(K)<1$, if $K>1$. Correspondingly, the derivatives in (ii) follow from $1 / 2(1)=1 / 2\left(K^{x}\right)=1$; and $1 / 2(K)>1$, if $K<K^{x}$ or $K>1=K^{\star} ; 1 / 2(K)<1$, if $1>K>K^{\star}$ or $1 K^{x}>K>1$. (See Lemma 1).

Q.E.D.

A ppendix 3: Proof of Lemma 2.

Let $\mathrm{x}^{\prime} \quad\left(\mathrm{K}_{1} ; \mathrm{C}_{1} ; \mathrm{K}_{2} ; \mathrm{C}_{2}\right)$ and the dynamical system (21)-(24) be written in matrix notation as $\dot{x}=f(x)$. Furthermore, let $y^{\prime}\left(\ln C ; \ln K ; K_{1} ; C_{1}\right)$ and

$$
g(y), \begin{array}{ccc}
0 & \left.a_{1} \ln 1 / 2 K\right) & 1 \\
& \left.\frac{a_{1}}{ \pm} \ln 1 / 2 K\right) i a_{2} \ln C+a_{2} \ln K \\
1 / 2\left(K_{1} ; K\right) i & \quad C_{1}\left(K_{1} ; K\right)
\end{array}
$$


where we use

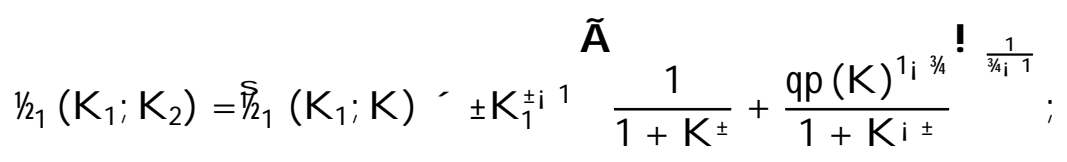

with @ $1 / \frac{1}{2}=@ K_{1}<0$, which follows from (5), (11), (12), and (13). ${ }^{48}$ De.ne the invertible matrix $h$ in the following way:

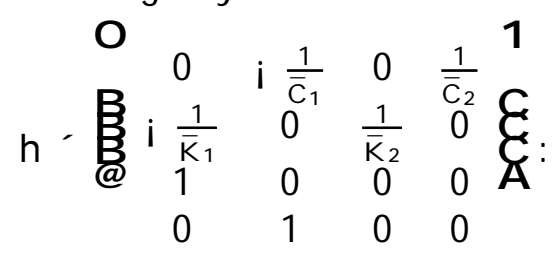

Then, we ..nd for $x$ and $y$ in the neighborhood of $\bar{x}$ and $\bar{y}$ that

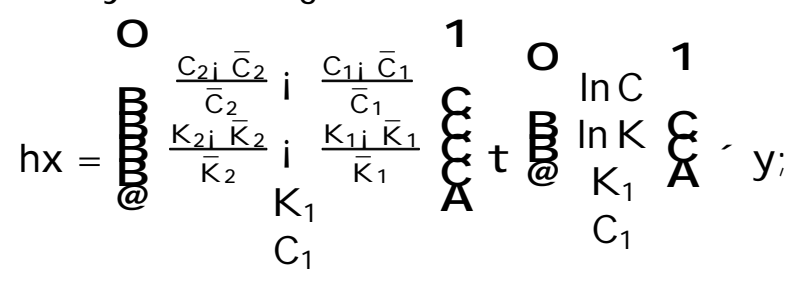

where we used the ..rst-order Taylor expansions

$$
\begin{aligned}
& \ln \mathrm{K}_{2} \mathrm{i} \ln \mathrm{K}_{1} \mathrm{t} \frac{1^{3}}{\overline{\mathrm{K}}_{2}} \mathrm{~K}_{2} \mathrm{i} \overline{\mathrm{K}}_{2},{\frac{1}{\overline{\mathrm{K}}_{3}}}^{3} \mathrm{~K}_{1 \mathrm{i}} \overline{\mathrm{K}}_{1} \\
& \ln C_{2} i \ln C_{1} \text { t } \frac{1}{\bar{C}_{2}} C_{2 i} \quad \bar{C}_{2}: \frac{1}{\bar{C}_{1}} C_{1 i} \quad \bar{C}_{1}
\end{aligned}
$$

around the steady state vector $\bar{X}$. Furthermore, we calculate the J acobian Matrix $B^{\prime} \frac{d g(\bar{y})}{d x}$ evaluated at the steady state vector $\bar{y}$ :

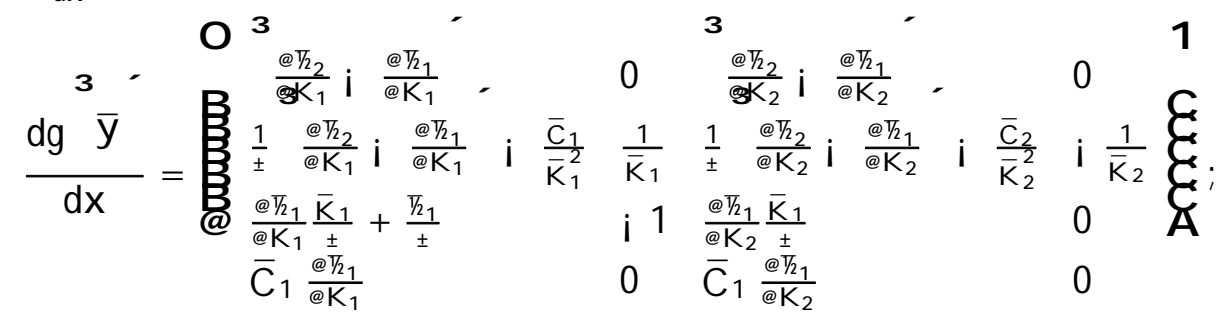

where we used the steady state conditions of (28), i.e.

$$
\begin{aligned}
& t / 3=1 / 2 ; \\
& \frac{\bar{C}_{1}}{\bar{K}_{1}}=\frac{\bar{C}_{2}}{\bar{K}_{2}} ;
\end{aligned}
$$

and by the rules of dixerentiation and (43):

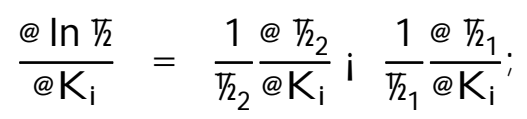

\footnotetext{
${ }^{48} \mathrm{R}$ ecall that bars denote steady state values of any steady state solution.
} 


$$
\begin{aligned}
& \frac{\mathrm{d}^{\mathrm{q} / \mathrm{z}}}{\mathrm{dK}_{\mathrm{i}}}=\frac{@^{ \pm / 3}}{\mathrm{GK}_{\mathrm{i}}} ; \\
& \frac{@ \ln \overline{\mathrm{K}}}{\mathrm{GK}_{1}}=i \frac{1}{\overline{\mathrm{K}}_{1}} \text {; } \\
& \frac{@ \ln \overline{\mathrm{K}}}{\mathrm{QK}_{2}}=\mathrm{i} \frac{1}{\overline{\mathrm{K}}_{2}} ;
\end{aligned}
$$

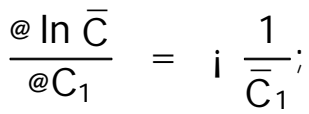

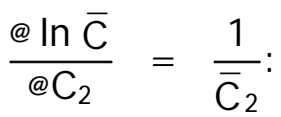

Correspondingly, the J acobian $A, \frac{d(\bar{x})}{d x}$ can be found from the linnearization of the dynamical system (21)-(24) around the steady state vectors $\bar{x}$ :

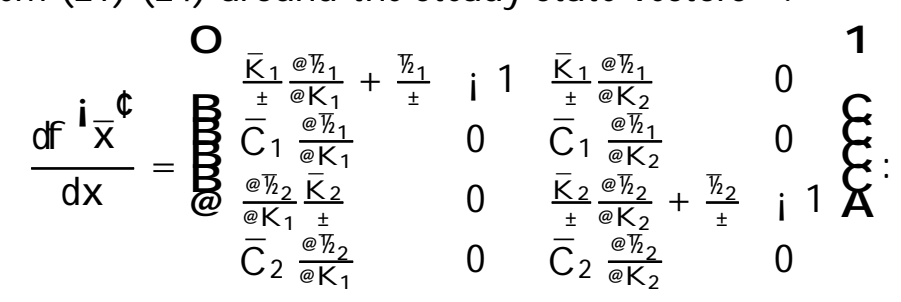

It can be checked that

$$
\frac{d^{3} \bar{y}}{d x}=h \frac{d^{i} \bar{x}^{\dagger}}{d x} \text {; }
$$

where we used (50) and

$$
\frac{\bar{C}_{i}}{\bar{K}_{i}}=\frac{z / z}{ \pm}
$$

for $\mathrm{i}=1 ; 2$, which follows from the steady state conditions of (21) and (23).

Now, we show that the J acobian $A, \frac{d(\bar{x})}{d x}$ and the J acobian $B{ }^{\prime} \frac{d g(\bar{y})}{d y}$ are similar matrices. ${ }^{49}$ Therefore, we need one more preliminary calculation. From the chain rule of matrix dixerentiation and (45) follows:

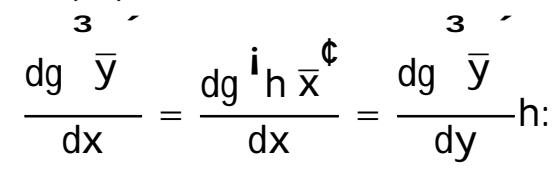

Because $\mathrm{h}$ is invertible, we can write:

$$
\frac{d^{3} \bar{y}}{d y}=\frac{d^{3} \bar{y}^{\prime}}{d x} h^{i} \text { : }
$$

Then, we may rewrite the J acobian B in the following way:

$$
B^{\prime}, \frac{d g \bar{y}}{d y}=\frac{d g \bar{y}}{d x} h^{i 1}=h \frac{d^{i} \bar{x}^{\dagger}}{d x} h^{i}{ }^{\prime} h A h^{i}{ }^{1} \text {; }
$$

\footnotetext{
${ }^{49} \mathrm{De}$ e.nition: If $A$ and $B$ are square matrices, we say that $B$ is similar to $A$, if there is an invertible matrix $h$ such that $B=h A h^{i}{ }^{1}$. (Brock and Malliaris, 1989, p.349)
} 
where the ..rst equality sign follows from (60), the second equality sign follows from (57), and the second identity follows from the de. nition of $A$. Therefore, the matrices $A$ and $B$ are similar. However, two similar square matrices $A$ and $B$ have the same characteristic polynomials and eigenvalues (Theorem 4.1 in B rock and Malliaris, 1989, p.349), i.e.

$$
j \mathrm{Ai}^{3} \mathrm{I}_{4} \mathrm{j}=\mathrm{jB} \mathrm{i}^{3} \mathrm{I}_{4} \mathrm{j}=0 \text {; }
$$

where ${ }^{3}$ denotes the eigenvector and $\mathrm{I}_{4}$ the $4 \mathrm{f} 4$ identity matrix. This concludes the proof.

Q.E.D.

A ppendix 4: Proof of Proposition 2.

Consider the Taylor linnearization of the system (29), (21), and (22), i.e.

$$
\dot{\mathrm{y}}=\mathrm{B} \quad \mathrm{yi} \quad \overline{\mathrm{y}} \text {; }
$$

where $y^{\prime}\left(\ln C ; \ln K ; K_{1} ; C_{1}\right), B{ }^{\prime} \frac{d g(\bar{y})}{d y}$ and $g(y)$ is de..ned in equation (42) of appendix 3. The characteristic polynomial of the matrix $B$ is found:

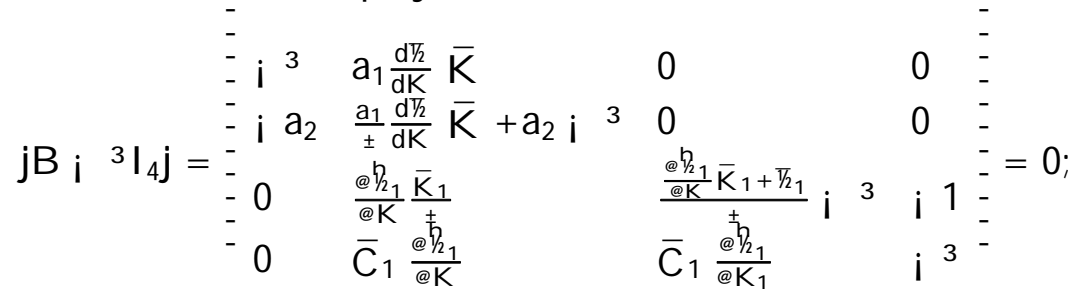

where ${ }^{3}$ denotes the eigenvector and $\mathrm{I}_{4}$ the $4 \mathrm{f} 4$ identity matrix. Next, a Gausstransformation with the Pivotelements $(1,1)$ and $(3,4)$ is undertaken and the second column is changed with the ..rst to form a matrix in Gauss-form:

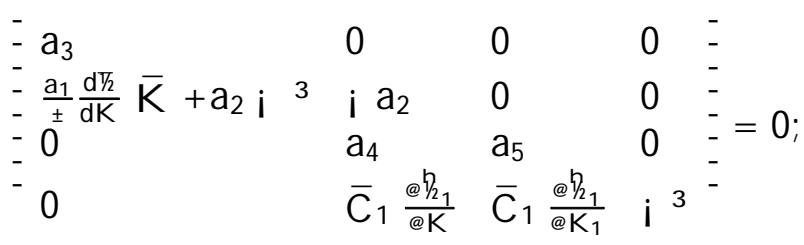

where we de..ned

$$
\begin{aligned}
& a_{3}, \quad a_{1} \frac{d^{z / 2}}{d K} \bar{K} i{\frac{3}{a_{2}}}^{\mu} \frac{a_{1}}{ \pm} \frac{d^{z / 2}}{d K} \bar{K}+a_{2} i^{3} \text {; ; }
\end{aligned}
$$

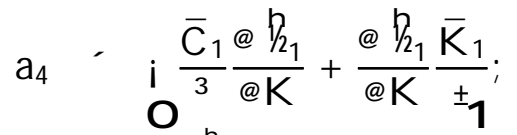

$$
\begin{aligned}
& a_{5}, @ \frac{\frac{@ / 2}{@ K} \bar{K}_{1}+1 / 3}{ \pm} ; 3 A ; \frac{\bar{C}_{1}}{3} \frac{@ 1 / 3}{@ K_{1}}:
\end{aligned}
$$

Because the determinant of a matrix in Gauss form is the product of its diagonal elements, the characteristic polynomial may be written in the following way:

$$
{ }_{32} i^{3} \frac{a_{1}}{ \pm} \frac{d^{t} / 2}{d K} \bar{K}+a_{2}+a_{1} a_{2} \frac{d^{t} / 2}{d K} \bar{K}=0
$$

or

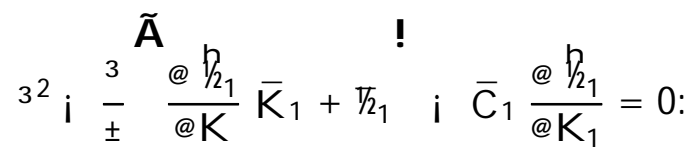


Correspondingly, the 4 eigenvalues are:

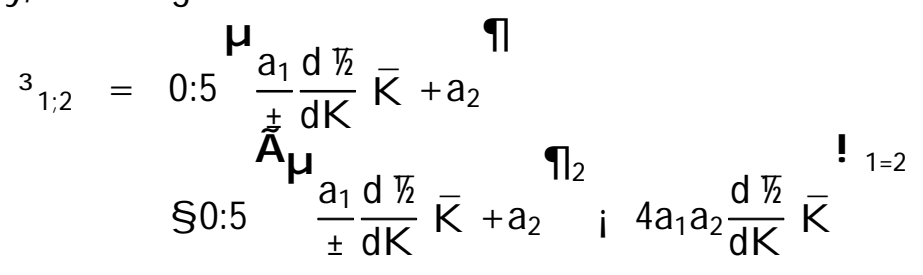

and

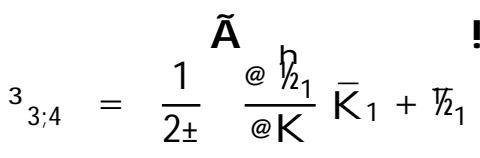

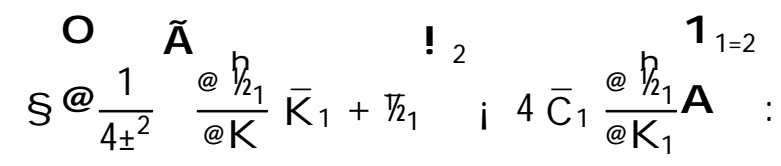

B ecause $@ \frac{1}{2}=@ K_{1}<0$, the last two eigenvalues are real numbers and can be ranked as follows:

$$
{ }_{3}^{3}<0<{ }_{4}^{3}:
$$

The ..rst two eigenvalues are evaluated as follows:

$$
{ }_{1}^{3}<0<{ }_{2}^{3} ;
$$

if

$$
\frac{d^{ \pm} / 2}{d K}<0
$$

and

$$
\begin{aligned}
& \operatorname{Re}\left({ }_{1}^{3}\right)>0 ; \\
& \operatorname{Re}\left({ }_{2}^{3}\right)>0 ;
\end{aligned}
$$

if

$$
\frac{d^{t} / 2}{d K}>0:
$$

Note that condition (72) is ful...lled in cases (i), (ii), and (iii) of proposition 2, whereas condition (74) is equivalent to the condition described in case (iv) of proposition 2 which follows from proposition 1.

Because the matrices $A$ and $B$ have the same characteristic polynomials (Lemma 2), the qualitative local stability properties are preserved by the transformation from the linnearization of system (63) to the linnearization of system (21)-(24). In particular, there exist two positive and two negative eigenvalues for system (21)-(24) in the cases (i), (ii), and (iii) of proposition 2 and 3 positive and 1 negative eigenvalue in case (iv). There correspond stable (unstable) eigenvectors to the stable (unstable) eigenvalues. By the stable manifold theorem, the local stable manifolds for the local steady states $x^{\sharp} ; x^{\natural x}$; and $x^{x \sharp \sharp}$ of cases (i), (ii), and (iii) are two-dimensional (i.e. a surface in $\mathrm{R}^{4}$ ), whereas the local stable manifold for $x^{\sharp}$ in case (iv) is one-dimensional.

Next, it follows from case 1 in Buiter (1984) that a unique solution to the boundary value problem (21)-(26) exists and is stable in cases (i), (ii), and (iii), because the number of positive eigenvalues is equal to the number of control (jump-) variables $\left(\mathrm{C}_{1} ; \mathrm{C}_{2}\right)$.

The boundary value problem (21)-(26) does not have a solution in case (iv), unless we give up one initial condition. Giving up the initial condition for $K_{2}(0)=K_{20}$ and 
letting $\mathrm{K}_{2}$ "jump", yields again a unique and stable solution. If we inspect (68), we see that these are the eigenvalues of the dynamical subsystem (29) which determines convergence/ non-convergence of $K$ towards the steady state $\bar{K}$. If these eigenvalues are both positive, there will not be convergence of $K$. Therefore we guess that the system (21)-(26) must be restricted in $\mathrm{K}_{2}(0)$, such that relative capital ratios are in their steady state right from the beginning. Formally, we guess that

$$
\mathrm{K}_{1}(0)=\mathrm{K}_{2}(0)=
$$

wills have to hold for any $2 \mathrm{R}^{+}$. For any time $\mathrm{t}^{\mathrm{s}}$, there exists $a^{\mathrm{s}} 2 \mathrm{R}^{+}$such that $\mathrm{K}_{1} \stackrel{\mathrm{s}}{\mathrm{t}}={ }^{\mathrm{s}}$ : By the property of autonomous dixerential equation systems, $\mathrm{t}$ can be normalized to zero. Therefore, (75) implies that

$$
\mathrm{K}_{1}(\mathrm{t})=\mathrm{K}_{2}(\mathrm{t})
$$

for $t$, 0 . From the ..rst equation of (28) follows then that

$$
\mathrm{C}_{1}(\mathrm{t})=\mathrm{C}_{2}(\mathrm{t})
$$

for $t, \quad 0$ : Furthermore, from (16), (17), and (76) follows that $p(t)=1$ for $t, 0$ : The system (21)-(24) collapses to the system of two independent neoclassical growth models. Therefore, the guess in form of condition (75) is valid and yields indeed a stable solution to the boundary value problem (21)-(26) without the initial condition $\mathrm{K}_{2}(0)=\mathrm{K}_{20}$.

Q.E.D.

\section{A ppendix 5: Proof of proposition 3.}

We start out with equations (21) and (23). They can be integrated taken $C_{j}(0)$, and $1 / 2(t)$ to be well-de..ned (though unknown) functions of time $t$ as given (Note: $C_{j}(0)$ is to be solved for.):

$$
C_{j}(t)=C_{j}(0) e^{\left.k / 1 / p(s)_{i},\right) d s}:
$$

Integrating in the same way (22) and (24) yields

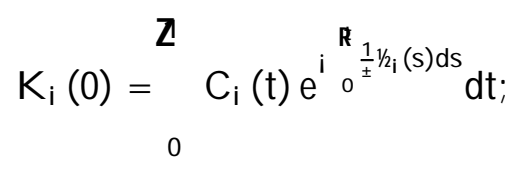

where we made use of the intitial condition (25) and the transversality condition (26). Plugging (78) into (79) yields:

$$
C_{j}(0)={ }^{1}(0) K_{j}(0) ;
$$

where

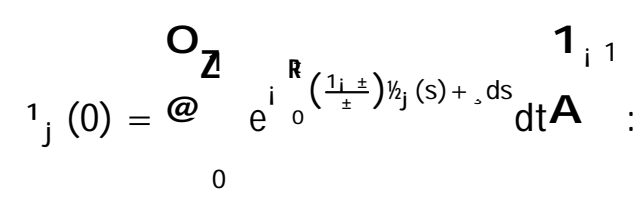

(The three steps are standard in the literature, e.g. Barro and Sala-i-M artin (1995), p. 59a., in a similar model.) Suppose now:

$$
\text { (i) } \quad \mathrm{K}_{10}=\mathrm{K}_{20}={ }^{\mathrm{s}} \text {; }
$$


with any ${ }^{\mathrm{s}} 2 \mathrm{R}^{+}$. Suppose further that with this initial condition the steady state $\mathrm{x}^{\mathrm{gx}}$ will be reached, i.e.:

(ii) $\quad \overline{\mathrm{K}}_{1}>\overline{\mathrm{K}}_{2}$;

i.e. $\bar{K}=K^{x}<1$ : Finally, we assume without loss of generality that $K(0)$

$\mathrm{K}$ for 0 S $1 .{ }^{50}$ From this assumption and proposition 1 follows that

$$
1 / \frac{1}{4}(s), 1 / \frac{z}{2}(s)
$$

for 0 s 1 and a strict inequality for some s. Consequently,

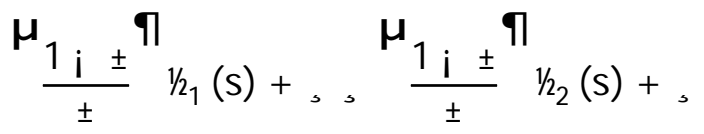

for $0 \quad$ s $\quad 1$ and a strict inequality for some s. One may check that this implies

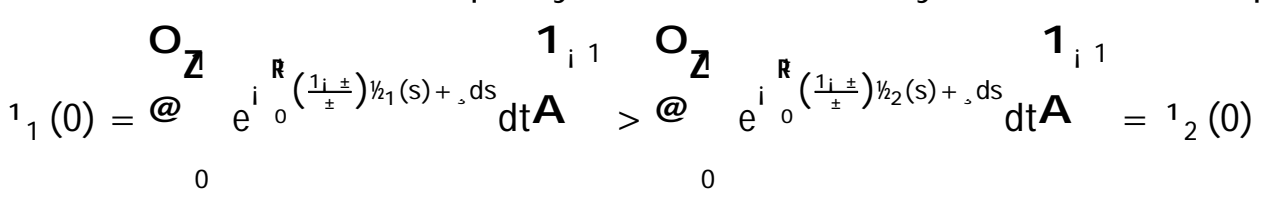

and therefore by equation (80) and assumption (i)

$$
\mathrm{C}_{1}(0)>\mathrm{C}_{2}(0) \text { : }
$$

However, then follows from (28) and assumption (i) that

$$
\dot{K}_{1}(0)<\dot{K}_{2}(0) \text {; }
$$

i.e. $\dot{K}(0)>0$. Recall that $K(0)=1$ (assumption i) and $K^{x}<1$. Therefore, the direction of movement will always point away from the steady state $K^{\star}$, if $K(0)=1$ : By the properties of an autonomous dixerential equation system, the trajectory to the steady state can never pass the threshold $\mathrm{K}=1$ at any point in time in the direction of the steady state and therefore not reach the steady state. This contradicts assumption (ii). Therefore, there is no perfect foresight path from the initial condition $\mathrm{K}(0), 1$ to the steady state $K^{x}$ : By the symmetry property of the model, there is also no perfect foresight path from the initial condition $K(0) \quad 1$ to the steady state $\left(1 K^{\natural}\right)$ : From proposition 2 case (iv) follows that there exists a one-dimensional stable manifold such that $\bar{K}=1$ is reached, if $K(0)=1$. This concludes the proof.

Q.E.D.

\footnotetext{
${ }^{50}$ In other words: If $K_{1}(s)=K_{2}(s)$ for $s 2$ f $s^{0} ; s^{\infty} ; \cdots:$, and $s^{0}, s^{\infty},::$ on the same trajectory reaching $x^{\not y}$ (if it exists), then we normalize by the property of autonomous systems $s^{0}=0$. Then follows that $K_{1}(s)>K_{2}(s)$;i.e. $K(s)<1$, for $s>0$, because $s=0$ is the last point in time, where $K_{1}(s)=K_{2}(s)$ is sustained and before the steady state $K^{x}<1$ is reached. Furthermore, $x^{\text {ax }}$ is a stable node which follows from the proof of proposition 2 . Therefore, the steady state value is not "overshooted" (as would be the case for a stable focus), i.e. K (s), $K^{\text {" }}$ for $\mathrm{s}>0$.
} 


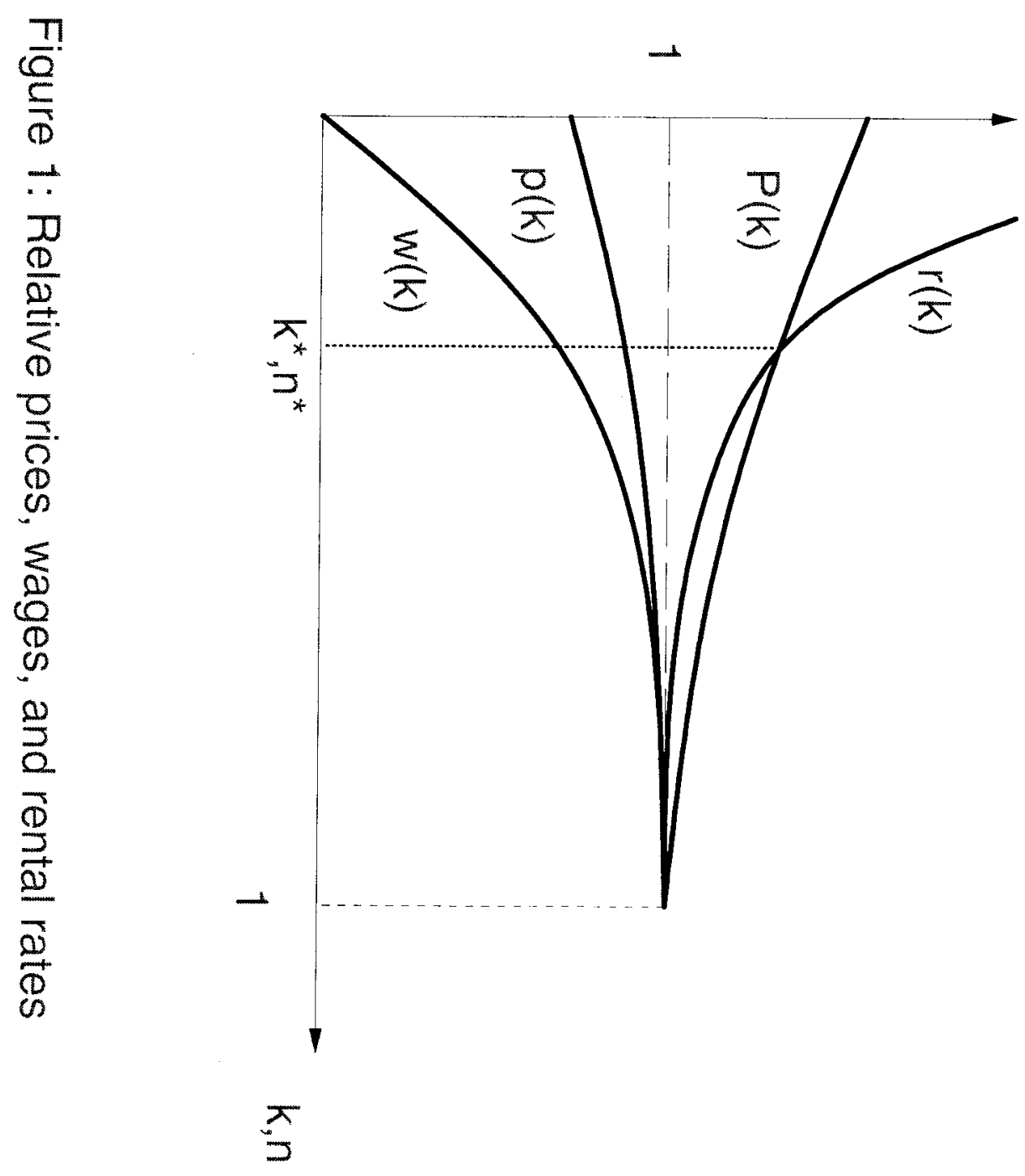

Figure 1: 


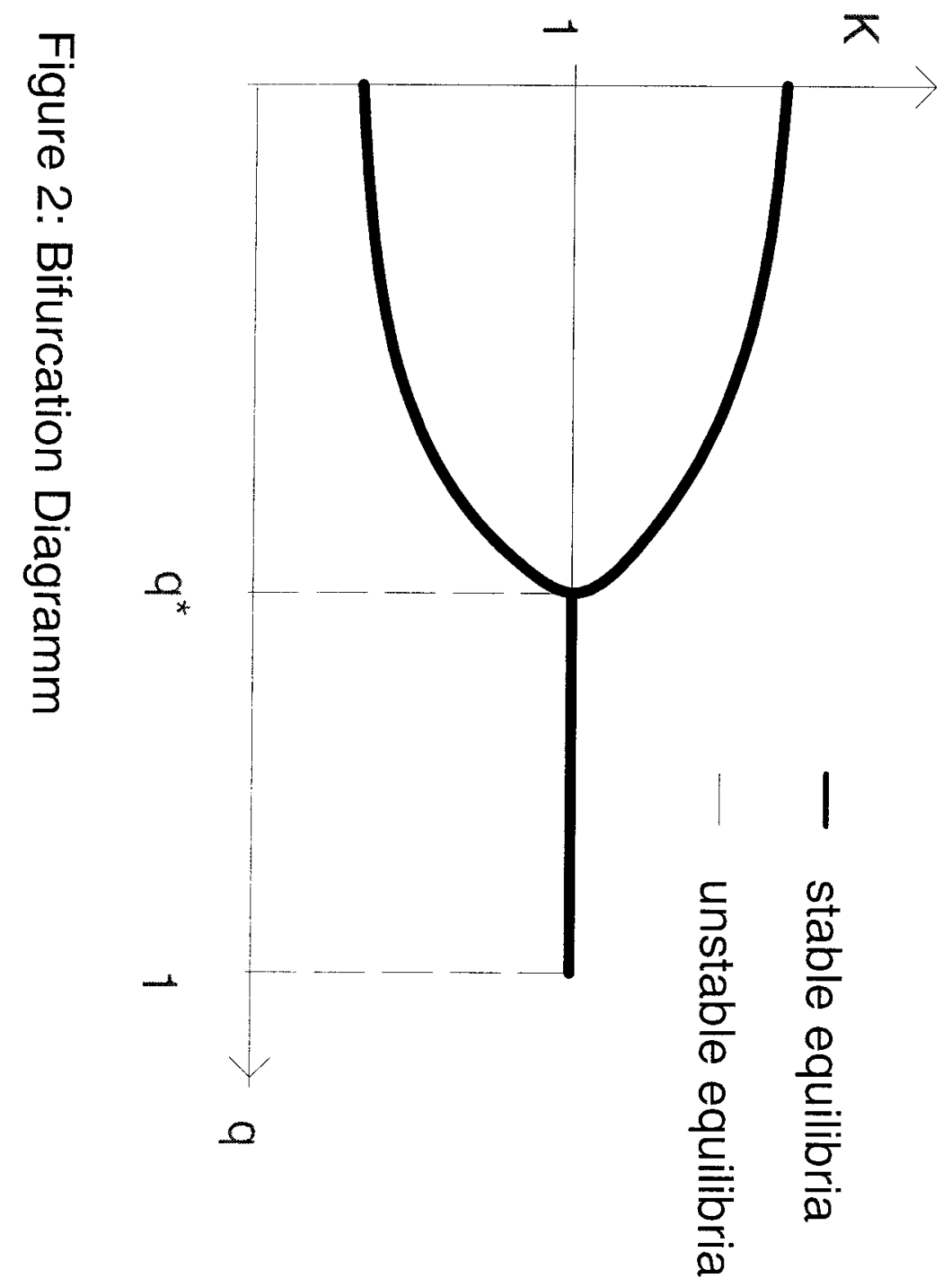

Figure 2: 


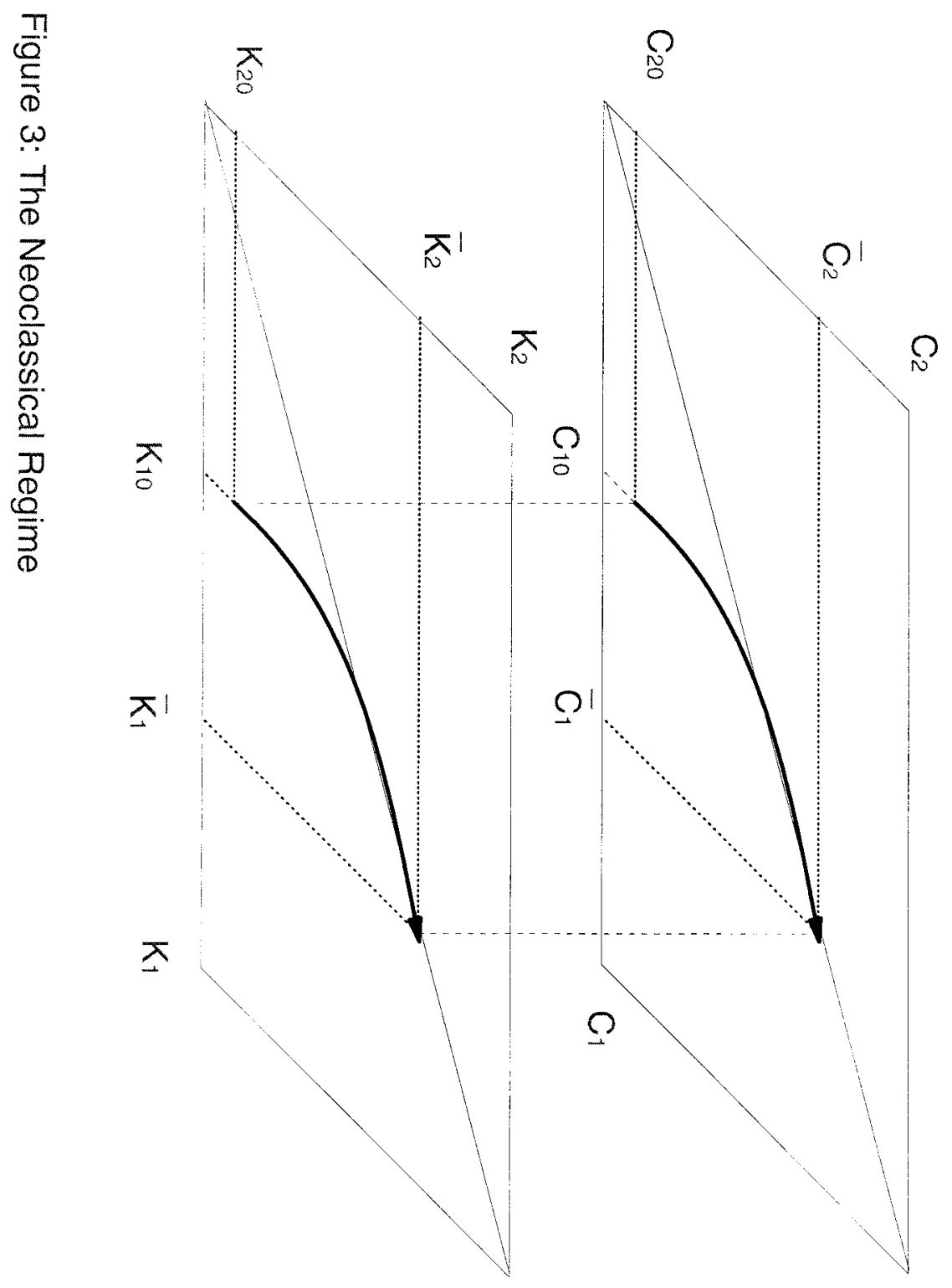

Figure 3: 

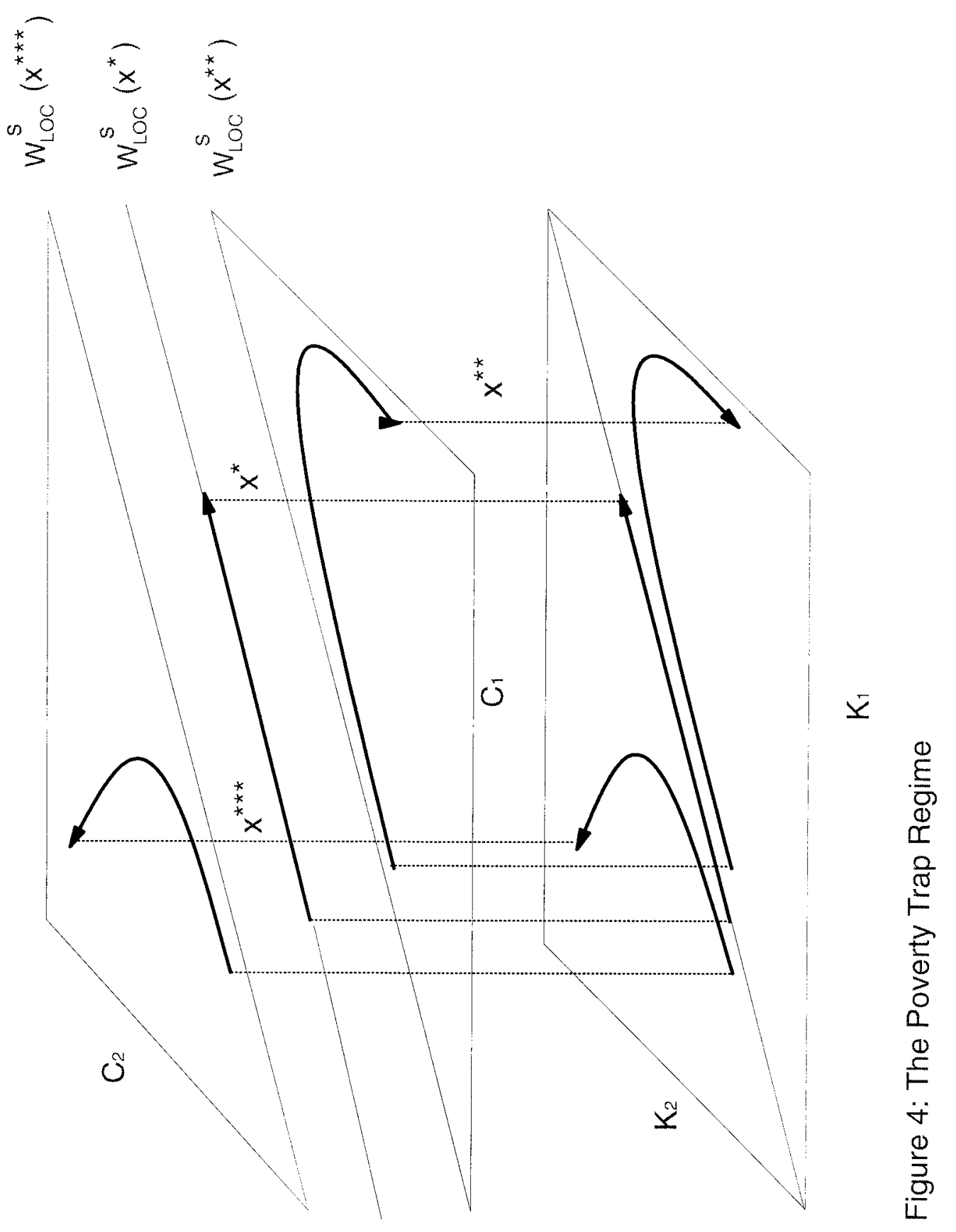

Figure 4: 